\title{
John Bintliff, Phil Howard
}

\section{A Radical Rethink on Approaches to Surface Survey and the Rural Landscape of Central Greece in Roman Times}

The Boeotia regional project began in 1978, and on completion of the final fieldwork campaign in 1997 had mapped some 250 rural sites and four larger, urban sites (for a recent cumulative bibliography cf. Bintliff, 1998). This paper will focus on the rural hinterland of the largest city site examined - ancient Thespiae. The city itself was completely surface-surveyed in 1985-6, and proved to be surprisingly large - over 100 hectares densely occupied. Although the final mapping of urban surface finds by date is still in process, preliminary plotting of a representative portion of the data (Bintliff, Snodgrass, 1988a; Snodgrass, Bintliff 1991) showed that the town reached its maximum occupation size in Classical Greek times (later Archaic to Early Hellenistic phases), then shrank to between 1/2 and $1 / 3$ of its surface by Early Roman times, to remain at that size throughout the Late Roman period (5th-6th centuries $A D$ ). In subsequent years of our project fieldwork, surface survey of the city's rural hinterland to the south was carried out over an area of $5.2 \mathrm{sq.km}$ (figure 1), resulting in the discovery of 18 locations designated as 'sites' by field-teams (on the basis of unusual quantity and/or quality of surface finds, primarily of pottery and tile). These sites had a very specific chronological profile: none were initially recognised to be prehistoric, one had a major Medieval phase, and 17 of the 18 were Greco-Roman in date. On a revaluation of the nature of the taphonomic processes affecting prehistoric sites we are now inclined to see some half-dozen of these sites as vestigial small farmsteads in Bronze Age times (Bintliff, Howard, Snodgrass, 1999). In this paper, however, we shall focus on the much more abundant and representative ceramic finds of Greco-Roman times and the nonetheless equally complex problem of their interpretation in activity terms.

The most obvious question one might ask is whether surface 'sites' are quantitatively denser than surrounding fields where past human activity is argued to have been lighter and non-focussed. The Boeotia Project used a 'non-site' survey methodology (Bintliff, Snodgrass, 1985) where the density of surface artefacts was recorded continuously across the entire surveyed landscape, together with measurement of variable soil visibility to allow for density corrections. With the help of GIS (Arch-Info and Arch-View in our case) it is relatively easy to compare 


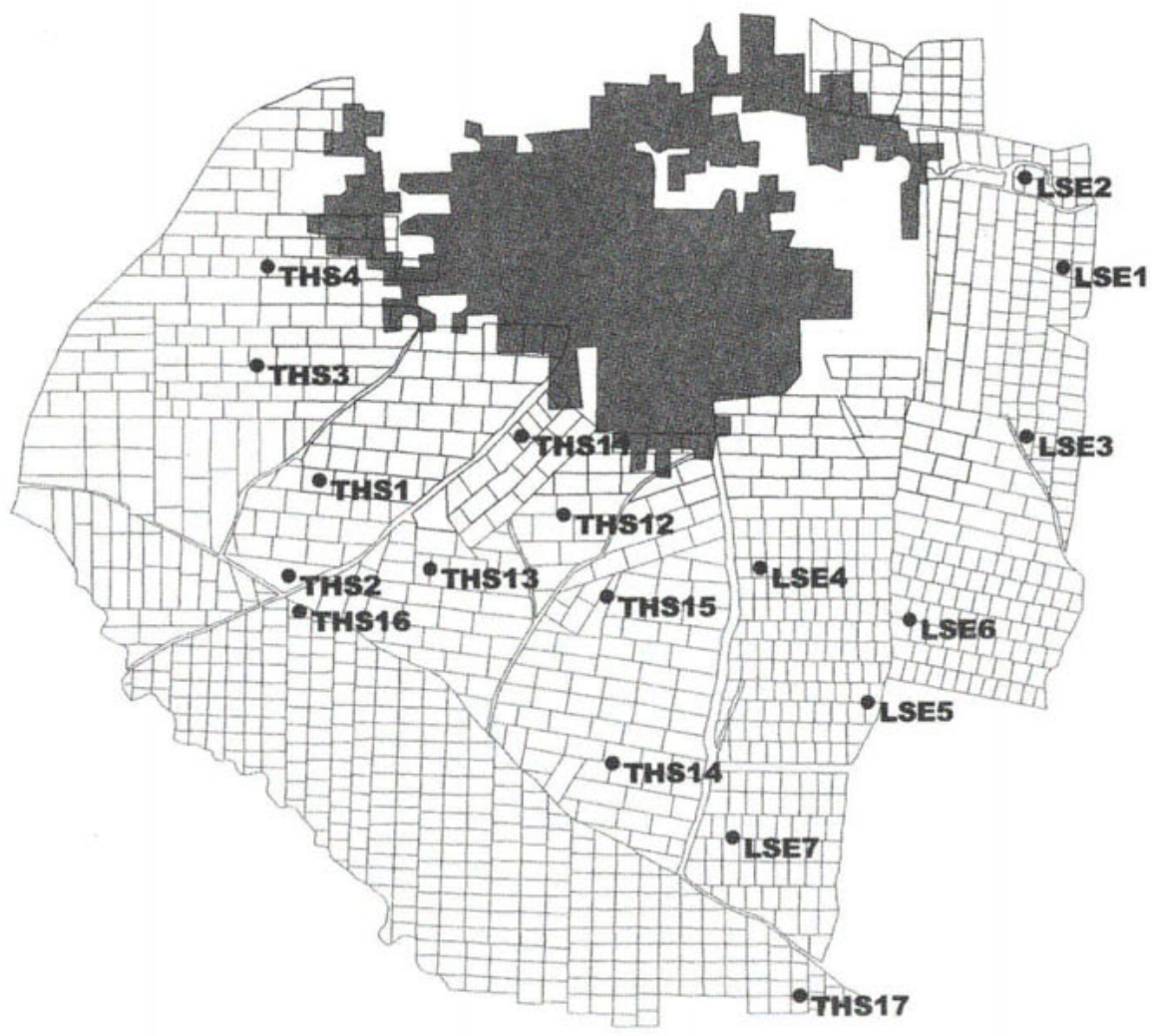

\section{Area $5.2 \mathrm{sq} . \mathrm{km}$}
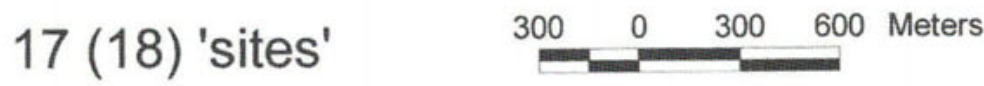

Fig. 1

the density of artefacts at defined radii from the approximate centre of a putative activity focus or 'site'. In figure 2 we show cumulative percentage curves of surface ceramic density (in sherds per hectare, visibility-corrected) for successive radii in $50 \mathrm{~m}$ intervals up to $150 \mathrm{~m}$ out from the site core. For comparison the density distribution of all the district offsite fields (minus the fields containing 'sites') is shown. It can be seen that densities rise as one approaches sites, and even at $150 \mathrm{~m}$ radius from a typical site, densities are above regional average - which together with the progressive density fall-off from the site proper point to the exist- 


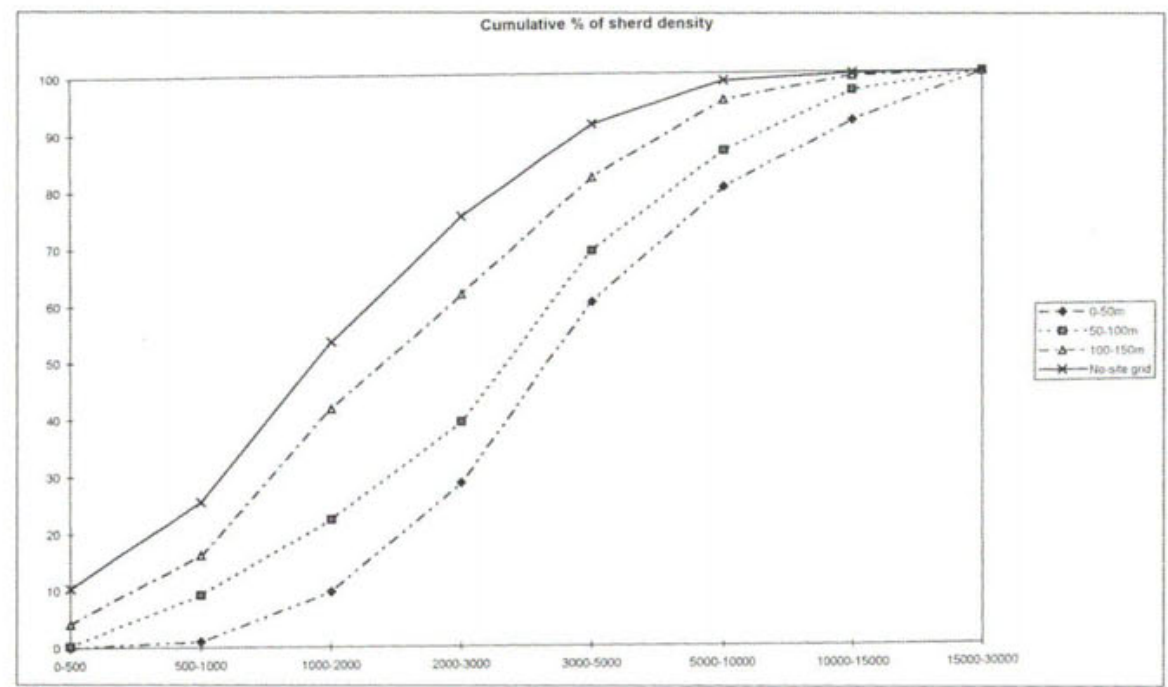

Fig. 2

ence of 'infield areas' or 'site haloes' in our data, argued to demonstrate intensive rubbish disposal and manuring in the immediate surroundings of the typical rural site. It might also be predicted that such 'halo effects' would vary with the size of site: Figures 3-4 separate small sites considered to be rural settlements and those

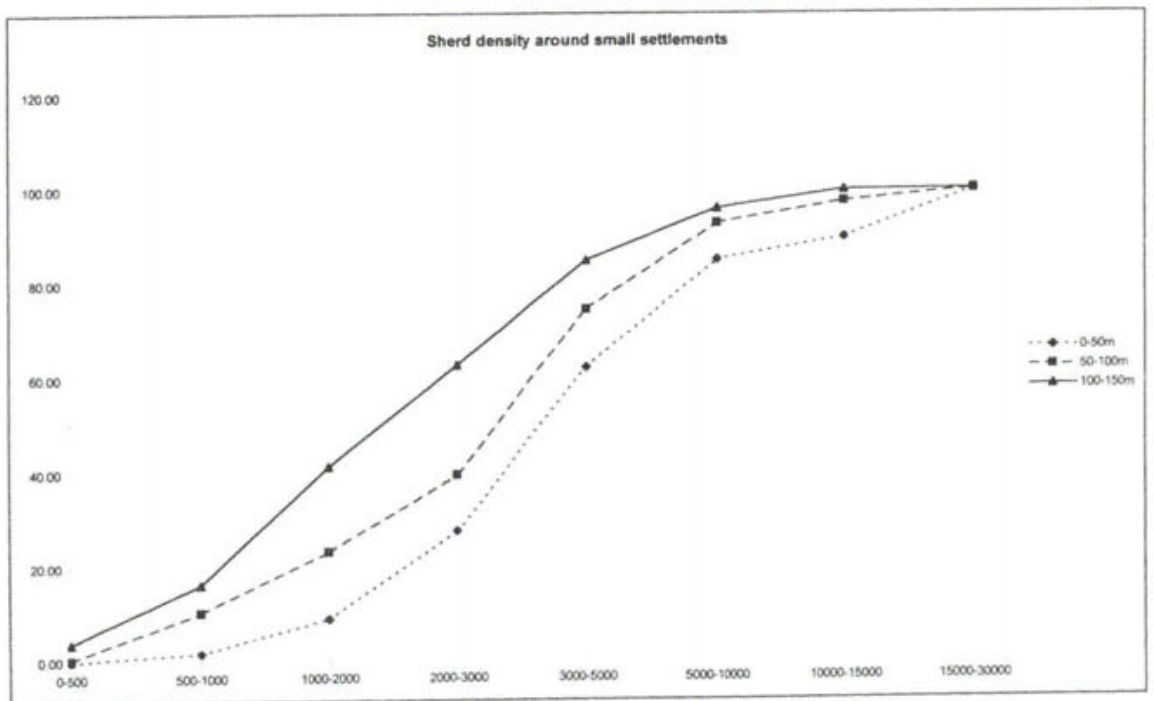

Fig. 3 


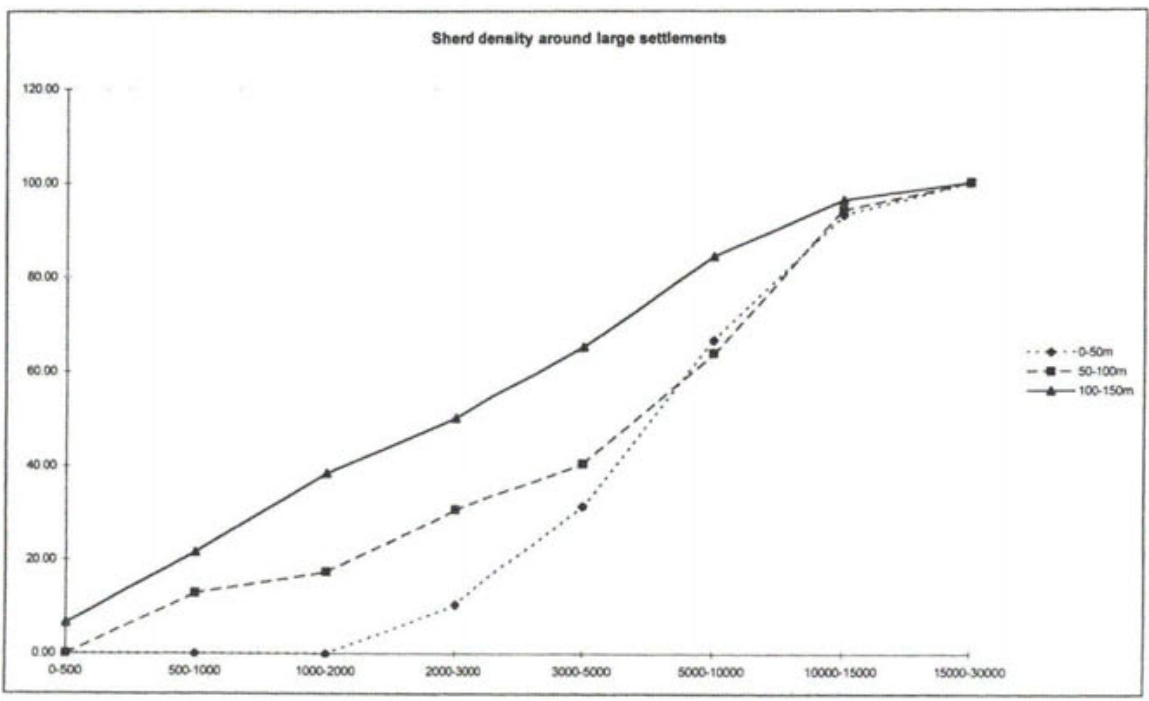

Fig. 4

considered as large rural settlements, showing as expected that sherd densities are both denser and more extensive into surrounding fields as settlements get larger. The surrounding densities of small settlements merge into the level of district offsite by $100 \mathrm{~m}$ radius, whereas those for large settlements are still above regional average at $150 \mathrm{~m}$ radius distance.

At this point what perhaps constitutes the most remarkable feature of Boeotian surface archaeology needs to be introduced: the staggering quantity of ancient pottery littering the agricultural landscape on a continuous basis for kilometre after kilometre (figure 5). As a result of total line-walking at $15 \mathrm{~m}$ walker-intervals we are able to display the total density across the landscape by field transect blocks, corrected for variable soil visibility (recorded on a scale of $1-10$, and corrected proportionately, i.e. a count of 5 sherds in a transect with ca. $10 \%$ soil visible due to vegetation cover $=$ count 1 , becomes a corrected count of 50). Because the sector under study is almost $100 \%$ agricultural land, visibility was rarely very poor, with crops and weeds being the main visibility-hindrances (average visibility count was around $50 \%$ i.e. 5). The average density of finds across the entire landscape of 5.2 sq. $\mathrm{km}$. is 2635 sherds per hectare (ie one sherd for every unit of $2 \times 2$ metres of landscape), or in total more than 1.37 million potsherds in the area under study here. If we consider that experiments in Boeotia have suggested that around $16 \%$ of ploughsoil finds lie on the immediate surface, the putative content of the ploughsoil assemblage would rise to a figure of some 8 and a half million!

With such staggering densities, it was decided to sample the surface material in the offsite sector for dating purposes, and in all 3714 pieces were collected in a rep- 


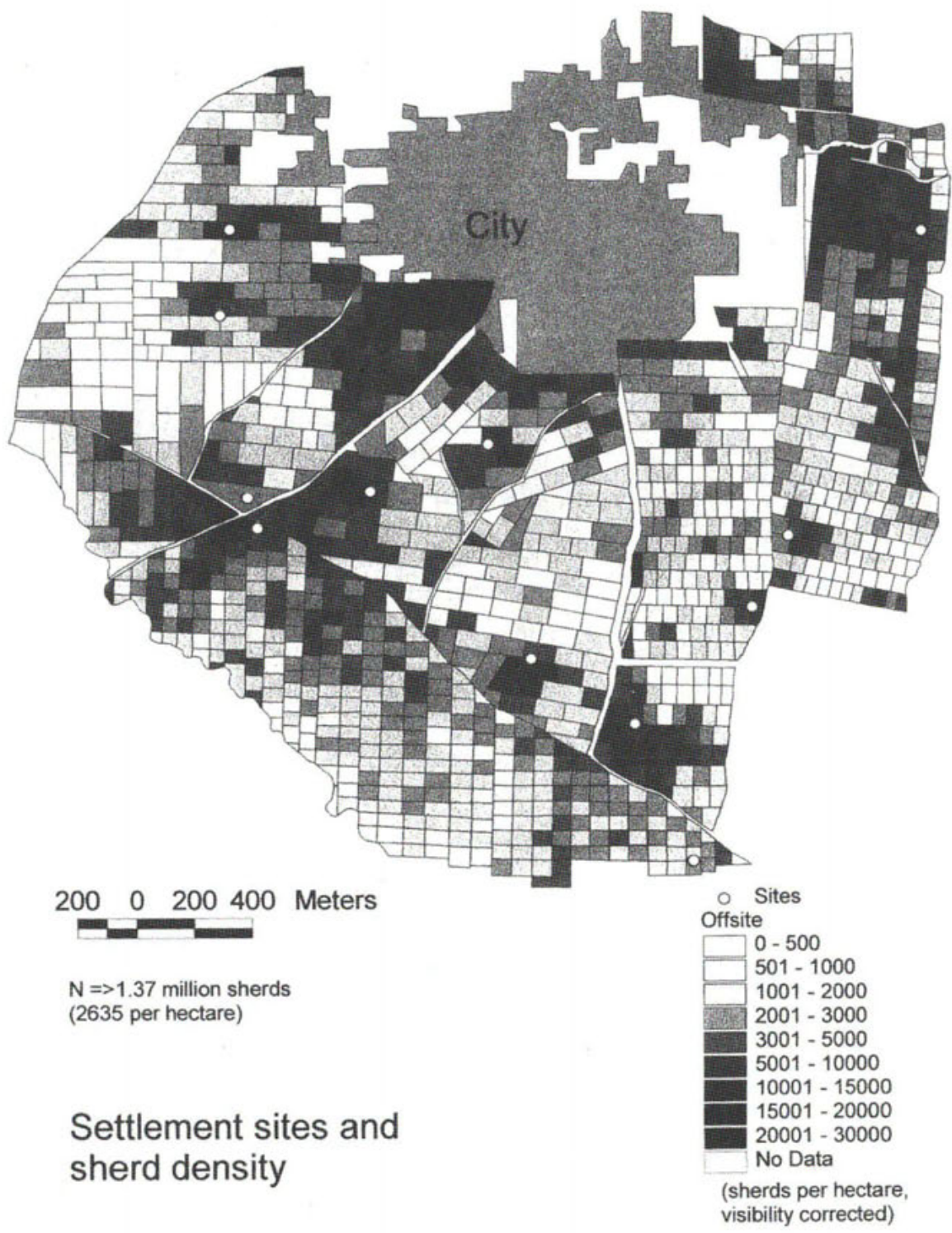

Fig. 5 
resentative way across the entire surveyed sector. Comparison of the spread and quantity of that sample by chronological phase (figures 6-9) revealed a surprising fact: the contribution of late Hellenistic-Early Roman, Early Roman and Late Roman finds was slight compared to the Classical Greek period (technically late Geometric to Early Hellenistic), with Prehistoric and Medieval-Modern even more insignificant. Some $\mathbf{7 0 - 8 0 \%}$ of all offsite finds belonged to that broad 'Classical' phase. Of course the dominance of human activity debris across the landscape during this one phase was not hard to account for, since we saw that at that time the city of Thespiae - in whose near hinterland we were working reached easily its maximal extent and hence inferred population.

We have in previous publications discussed at length the origin of such high offsite densities (cf. especially Bintliff, Snodgrass, 1988b; Snodgrass, 1994), attributing them unambiguously to intentional manuring using accumulated rubbish of organic and inorganic material stockpiled in ancient urban sites and rural estatecentres. The immense quantities implied by our recorded densities, confined to one phase of landscape occupance, can only emanate from the rubbish of a very large body of people. Our provisional population numbers for the rural sites in this sector - some $100 / 150$ people in Classical Greek times, pale into complete insignificance placed beside the estimate for the contemporary population of the city of Thespiae on the very edge of the surveyed zone to the north - perhaps 14000 inhabitants. There seems no doubt that the vast majority of offsite finds reflects the intensive manuring and hence cultivation of our sector by famers resident in the city, with much smaller inputs from the rubbish-heaps at rural sites within the sector itself. At this point we can usefully compare the deep impact suggested at Thespiae to a radius of at least 2 kilometres' manuring transport with figures produced by Tony Wilkinson (1994) for recorded agricultural manuring zones around Near Eastern sites he has studied, where cities over 40 ha in size show manuring scatters of several kilometres' radius.

GIS might be said to 'love' models with such direct spatial implications, such as this, so we have exploited its potential to investigate the manuring-effect more systematically. If most offsite material emanates from the city, we might expect to find rubbish transport to have been affected by distance and slope in relation to an hypothetical city farmer and his cart full of manure. We were pleased to find that most of the variability in offsite densities can be explained through reference to this trend, once we take out the clearly-defined site haloes that surround our recorded rural settlement sites. A lesser effect that emerged was an additional elevation in ceramics in a river valley in the southern part of the rural sector beyond the cost-surface prediction, pointing to heightened manuring in an unusuallyfertile area of fields despite its relative distance from the city. We are currently exploring the fine-detail of this model by linking micro-variation in densities to traditional agricultural tracks across this gently-rolling landscape. 

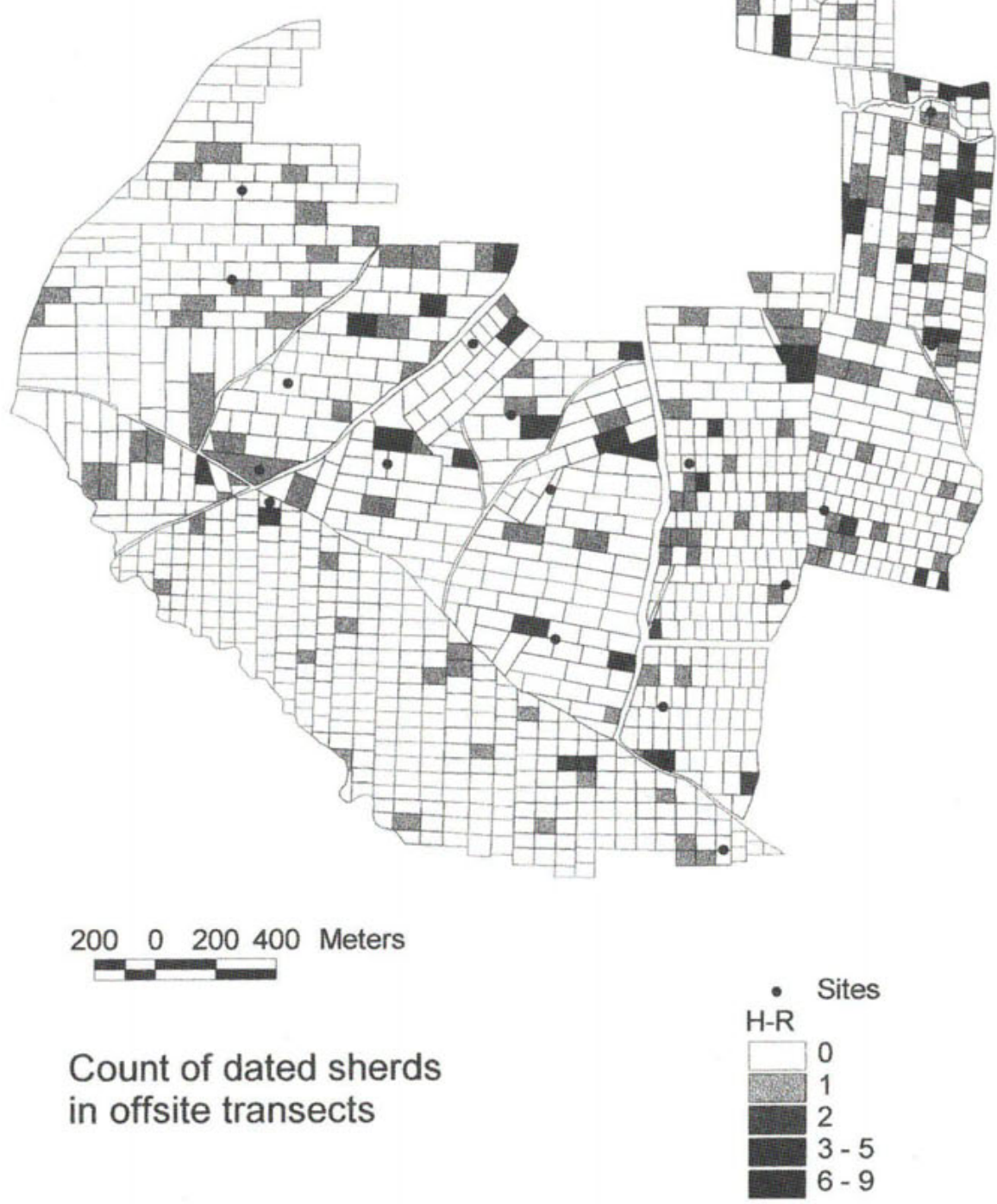

Fig. 6 

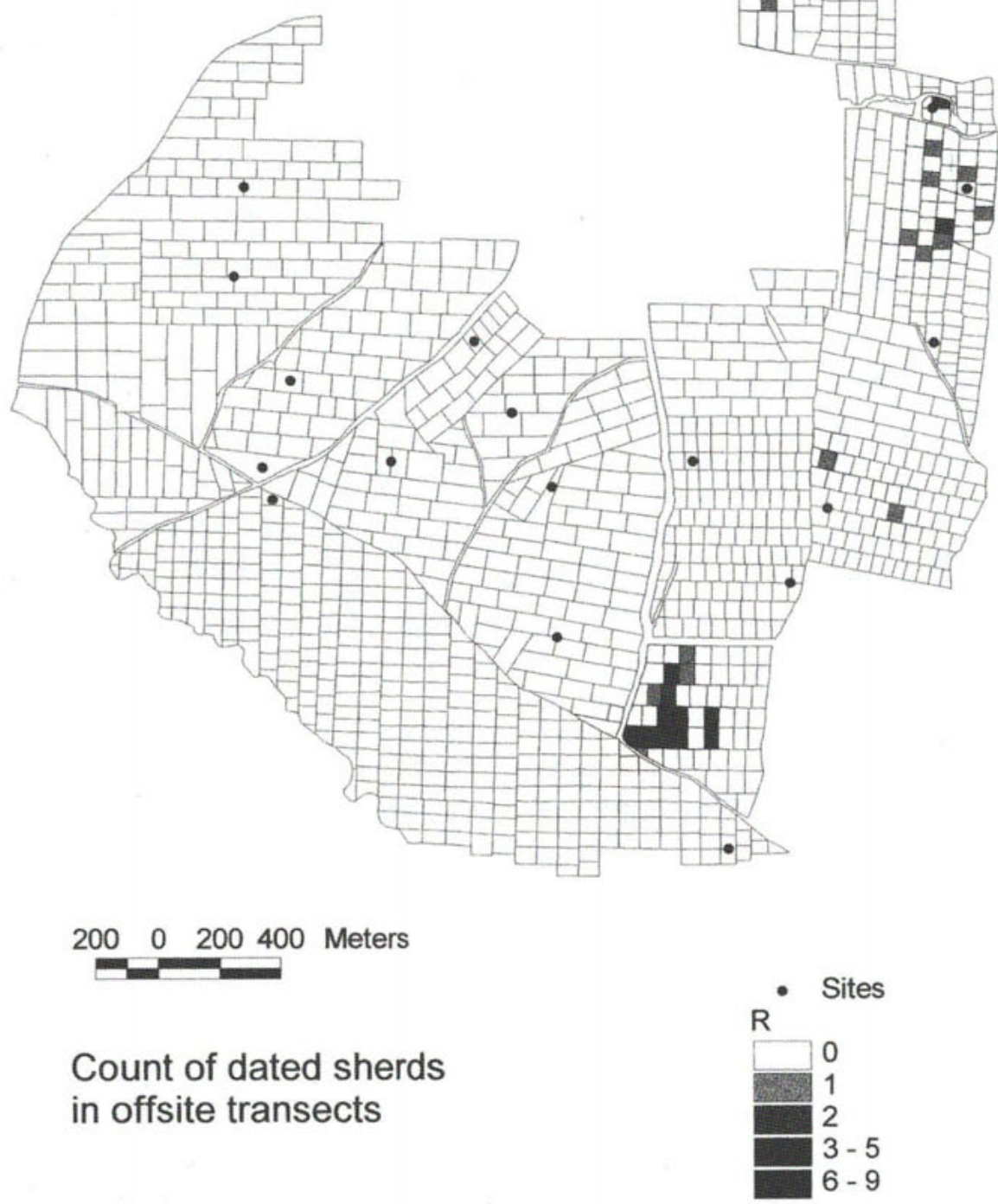

Fig. 7 


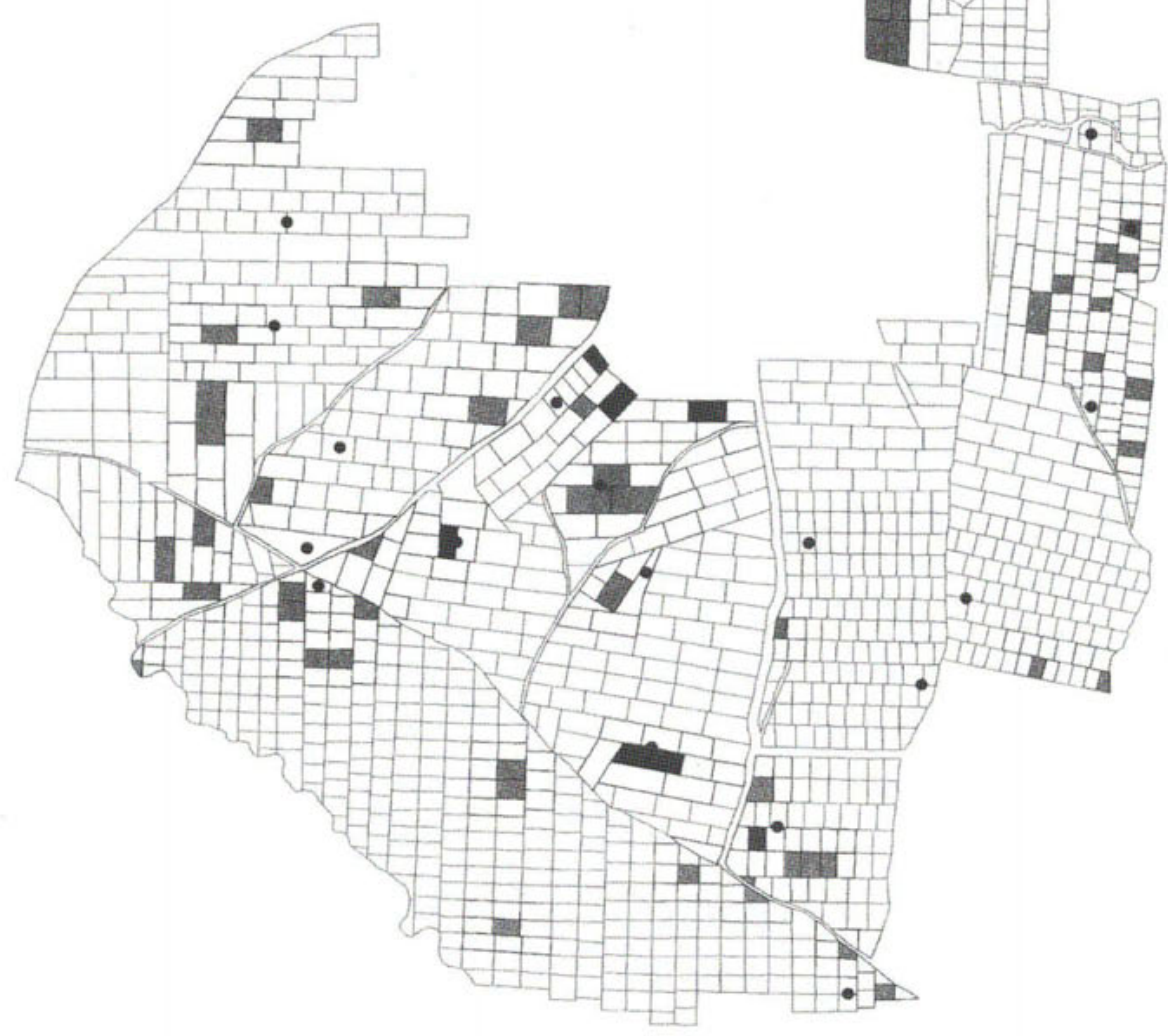

$200 \quad 0 \quad 200400$ Meters

Count of dated sherds in offsite transects

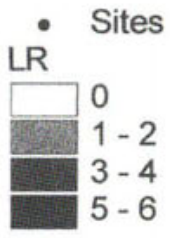

Fig. 8 


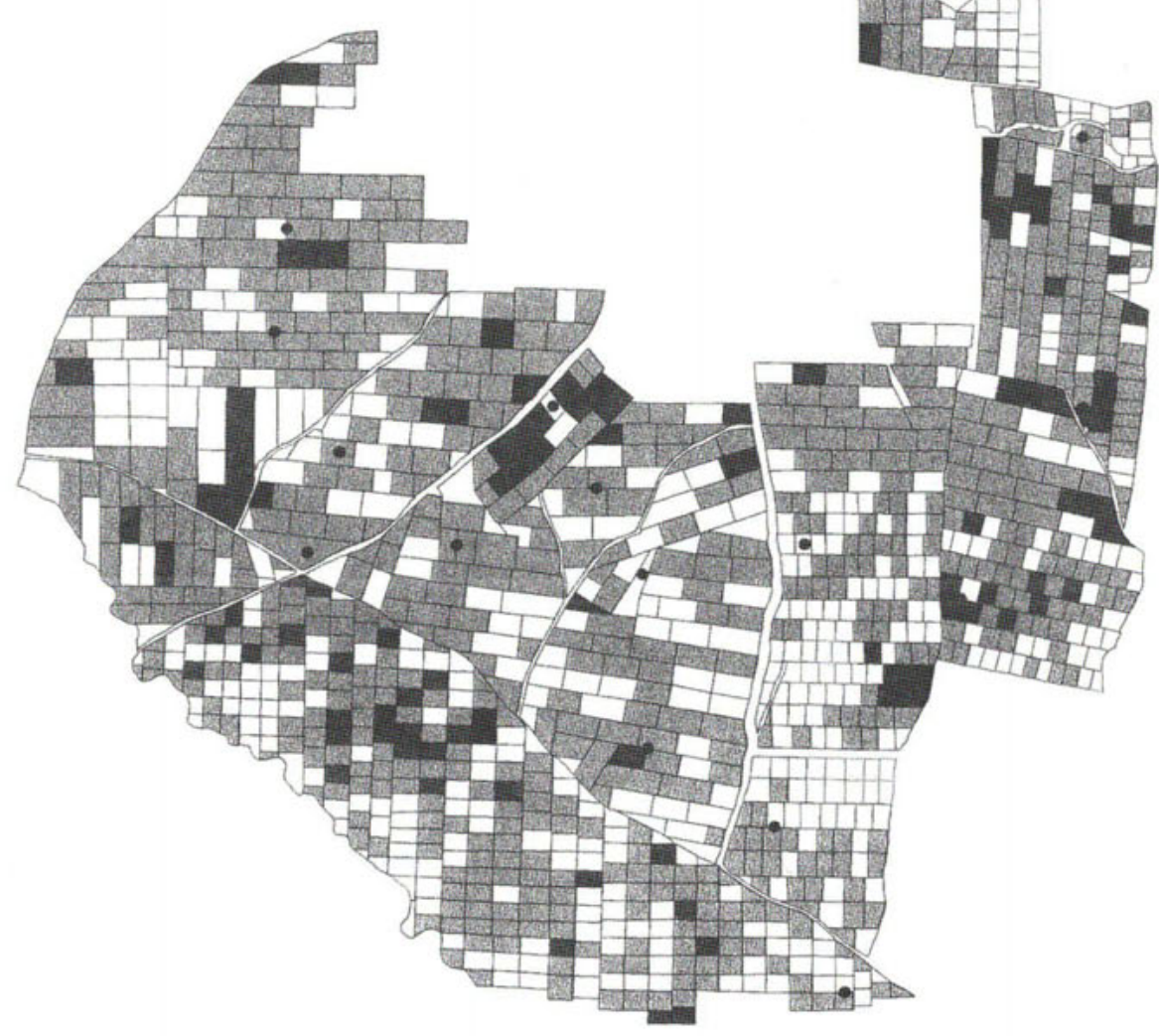

2000200400 Meters

Count of dated sherds in offsite transects

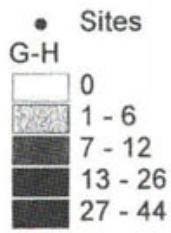

Fig. 9 
The analysis of individual sites

Some two years ago we were at an advanced stage of data synthesis for the surface finds from Boeotia sites, with tables of sherds per phase for each site. However we were confronted by the problem all recent intensive surveys have reached at publication stage - the significance of variable numbers of finds per period at the same location. Figure 10 illustrates the problem well: 'site 64 Otzias' from the Keos Survey publication (Cherry et al., 1991). The dated collection was small and multiphase, especially for a 2 hectare site. Very slight numerical differences between dated finds for each period led to a rather arbitrary decision to allow confirmed site-level activity for only two phases of the seven or so potentially-represented in the sample collection.

\section{SITE 64. OTZIAS}

Area: approx. 2.0 ha.?

\section{Confirmed activity: Late Roman; Middle Byzantine}

\section{Dated finds from the site as collected: Greco-Roman 2+; Archaic-Classical 1; Archaic-Hellenistic 2 (plus +1?); Classical-Hellenistic 2; Classical-Late Roman 2 (plus 1+?); Late Roman 4+ (plus 1+?); Roman 1; Middle Byzantine 4; Modern 1+; Hellenistic-Roman 1}

\section{(From: Cherry, Davis \& Mantzourani, 1991)}

Fig. 10

Since Boeotia has a perhaps unparalleled carpet of offsite finds, one of the first things we need to do is clarify the parameters of that general landscape activity so as to set into context the density and then chronological makeup of the finds recovered from the sites themselves. In other words, were the site not to have been there, what level of offsite discard might be expected across its surface and of what chronological mix. Clearly some significant amount of pottery from our sites is actually a consequence of that general landscape carpet discovered earlier, rather than being a direct result of site activity and related halo activity proper. How easy is it, in fact, going beyond the cumulative frequency-graphs for all sites shown earlier, to isolate the 'site effect' on the maps of offsite finds across the whole district?

We have been able to make good progress in this aspect. Figure 11 shows our site LSE1, which is quite close to the eastern edge of the ancient city and medieval 

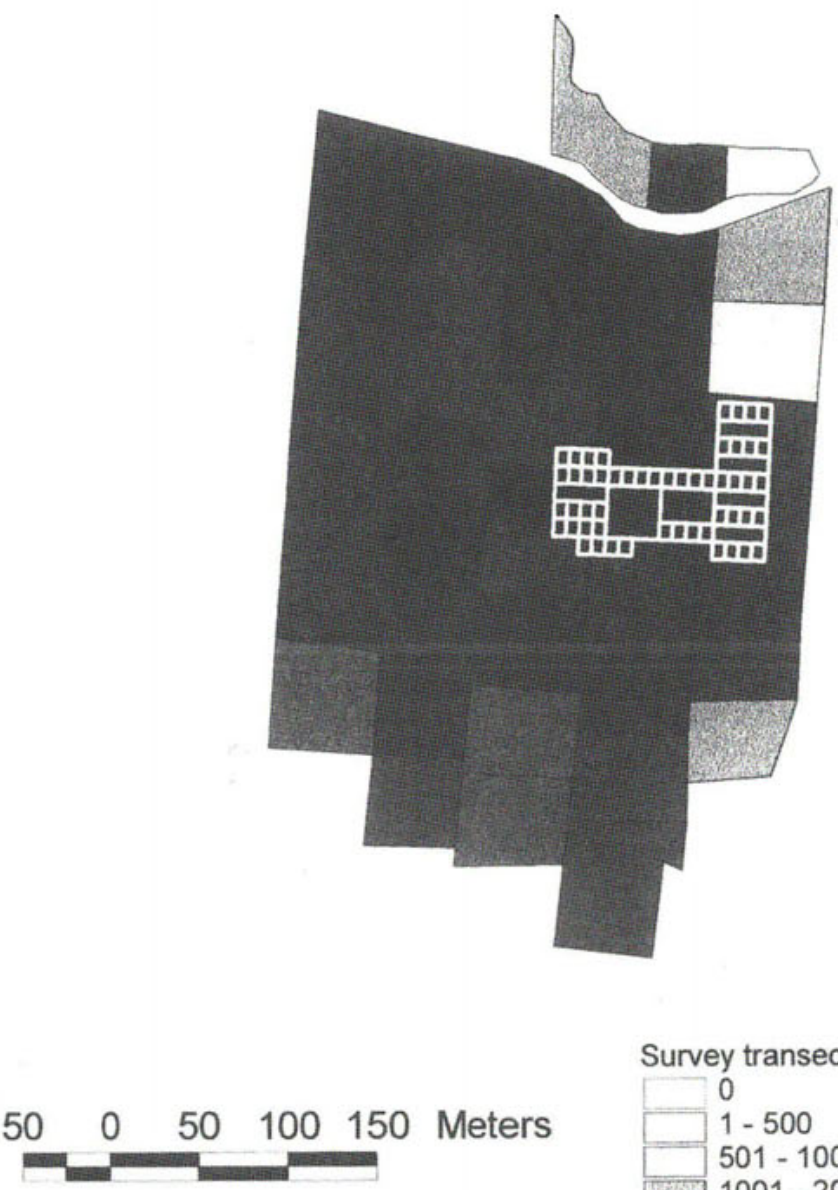

LSE1

Survey transects within $200 \mathrm{~m}$ of LSE1

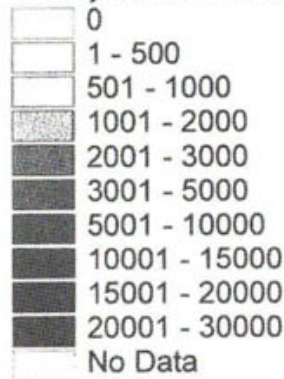

Fig. 11

village of Thespiae. The shading in sherds per hectare is dominated by a trend of increasing density as we approach the city to the left of the diagram, so that the site grid lies in a density sector that is essentially controlled by very high citybased manuring. Only in the east or right-hand edge of the site, where the general high-density carpet begins to drop off rather rapidly, can we see a higher-than- 
expected patch of density associated with the site. What we appear to be seeing here is a site-halo that is submerged below near-city manuring until its eastern rim, where it emerges to view. The $200 \mathrm{~m}$ density histogram not surprisingly produces figures all of which fall above the regional average for the whole LSE/THS district offsite. Clearly the lesson here is that 'offsite' impact on the site collection is likely to have been considerable, and needs calculating before we take the sherds collected at the site as a reflection of a localised activity focus.

As we move increasingly further away from the city we would expect to see the city-manure affect decreasing, allowing both sites and site haloes to stand out more markedly against local 'background' densities. Site LSE3 (figure 12) provides a good illustration. We can note here how the extensive site halo is clearly above the characteristic density level of local offsite, and also how both the site and its halo seem to lie in association with a modern farm-track. If haloes show parts of a rural estate given heightened manuring-treatment then these effects seem to be showing us the 'infields' given preferential fertiliser by the estateowners or managers of the sites concerned.

A not-uncommon site-type from our survey has been that of small rural cemeteries, mainly of general Classical Greek date - when appropriately the greatest level of human activity traces occur in the countryside (both at the site and offsite level). These are very difficult to spot through standard recognition of surface sites, since their surface debris is limited in density and spatial extent. Normally they have been located owing to one fieldwalker spotting a piece of unusually high-quality fineware in freshly-broken and recently-exposed condition (cultivation or other disruption having brought previously-protected grave goods into the ploughsoil). The spatial character of such sites is predictably quite different to sites where a range of indicators point to domestic, agricultural use. Figure 13 illustrates such a small burial site - LSE 4, in its immediate landscape context. Not only does the site (the area of narrow transects within the innermost, $50 \mathrm{~m}$ radius ring) not betray any impact on its surrounding background, but if anything it shows negative levels compared to the density range of the area around it. It is not difficult to account for this phenomenon: since the vast majority of offsite finds are of the same period as the cemetery, we might expect that a burial precinct would have been left out of the intensive manure and cultivation programme, so that it should indeed be below local density expectation. It is salutory to note the implications: apart from the almost accidental spotting of rare fineware in very small patches of landscape, such sites are unlikely to catch fieldwalkers' attention even in areas such as this - where background is relatively low; closer to large rural sites or urban sites, the chances of discovery become even more improbable. Any density-based methodology for site-definition (as applied for example by Carreté et al., 1995) will also fail completely in the face of these kinds of surface site.

At the core of the site 'phenomenon' (with or without a halo), gridded counting of surface finds usually allows us to distinguish areas of greater or lesser discard activity. When - as is normal with domestic sites - density levels are well-above local background, we can be confident that the general contouring displayed is the 


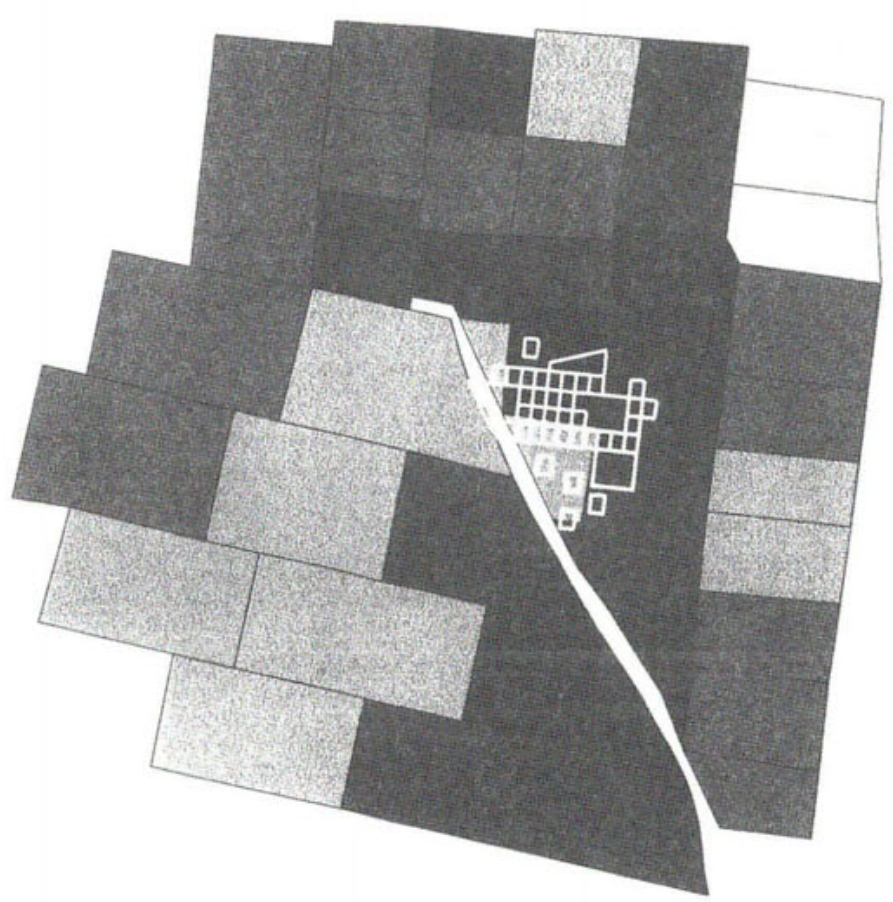

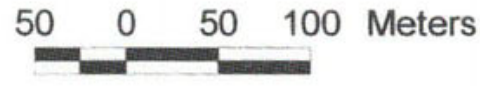

LSE3
Survey transects within $200 \mathrm{~m}$ of LSE3

\begin{tabular}{|l|}
\hline \\
\hline \\
$1-500$ \\
$501-1000$ \\
$1001-2000$ \\
$2001-3000$ \\
$3001-5000$ \\
$5001-10000$ \\
$10001-15000$ \\
$15001-20000$ \\
$20001-30000$ \\
No Data \\
\end{tabular}

Fig. 12 

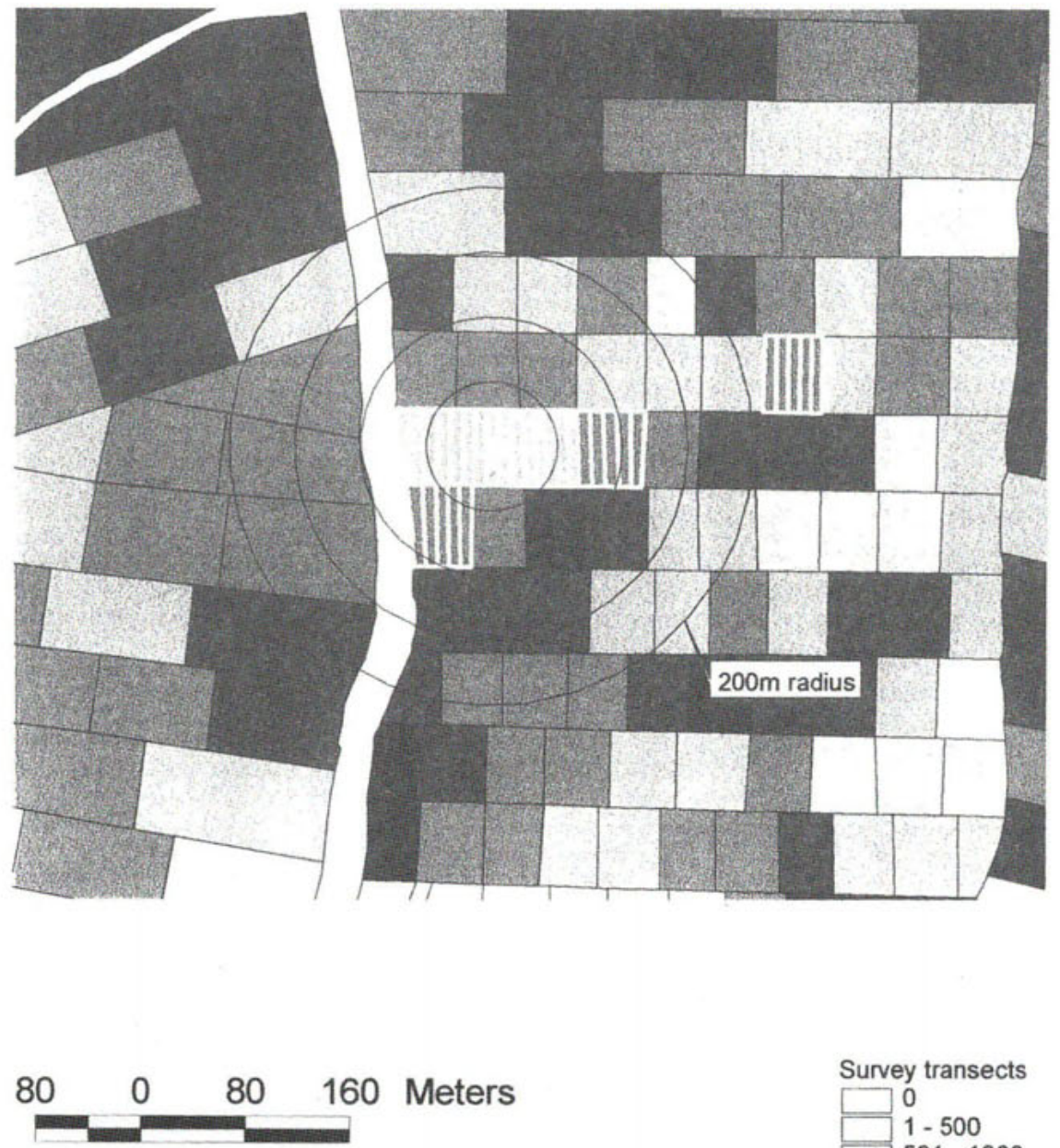

Survey transects

\begin{tabular}{|c|}
\hline 0 \\
\hline $1-500$ \\
\hline $501-1000$ \\
\hline $1001-2000$ \\
\hline $2001-3000$ \\
\hline 3001 - 5000 \\
\hline $5001-10000$ \\
\hline $10001-15000$ \\
\hline $15001-20000$ \\
\hline $\begin{array}{l}20001-30000 \\
\text { No Data }\end{array}$ \\
\hline
\end{tabular}

Fig. 13 
product of on-site activity rather than variations in offsite manuring or haloeffects from nearby sites. Figure 14 shows site LSE3 with a clear concentration of discard in the west-centre of the gridded area. On almost all the sites of this survey sector a separate density count was made of ceramic tile as opposed to other pottery, since empirical studies made previously on the Project showed that intra-site distinctions can frequently be made by plotting intense foci of this common Greco-Roman roofing-material. Figure 15, a dot-distribution of visibility-corrected tile finds, highlights a clear tile-focus in the upper part of the area just identified as the discard-heart of the surface ceramic finds. Obviously to suggest, as we would here, that a tiled building lies in a small part of the site (putatively the main residential farmhouse), the tile peaks should be enhanced over those of all ceramics. That is clearly the case here. In other parts of the Boeotia Project's surveyed area we have followed up such surface indications with largely successful geophysical study to pick up the plans of underlying farm-buildings (Bintliff 1992, 1997; Bintliff, Davies et al., 1990).

\section{Sample error and the residuality calculation}

Much mental effort has been expended on finding ways to cope with the rather intractable problem noted earlier in our illustration from the Keos Survey publication: how to deal with the complex numerical and chronological variety of finds from individual sites. Firstly, if one grids a site and then plots back the dated sherds after study, it is tempting to read any clusters of finds for a particular period as marking parts of the site in use at that time. This does not take account of the way in which most surface sites are sampled during fieldwork. Figure 16 will serve as an example. On the site grid we have mapped the percentage of finds collected for dating purposes compared to the counted density for each sample rectangle. The field team spent different amounts of time in each collection unit, were more then less enthusiastic about how much material they bagged for study; visibility conditions and the apparent diagnosticity of typical finds will also have affected sampling. In any case, it is more than helpful to have such a Sample Fraction Map alongside those showing the distribution of dated finds, so that we can try and control for clusters of finds arising from larger samples rather than genuine heightened activity in the past. In this case it is noteworthy that the dated collection varied from nothing brought back to base, through quite a few units with less than $10 \%$ collected, up to 3 units with over $20 \%$ collected. An application of this approach follows in figure 17, where we have displayed the spatial dispersal of dated finds from the same site for Early Roman times (R), as well as pottery dated to 'overlap' styles - Late Hellenistic to Early Roman (H-R) and Early to Late Roman (R-LR). We have marked the corner of sample units with above-average sample fractions as a guide to those units where sample error must be watched for. Although the apparent clustering of $\mathrm{R}$ finds in two areas - the north-centre and south-west zones - includes four high sample-fraction units, the clustering 


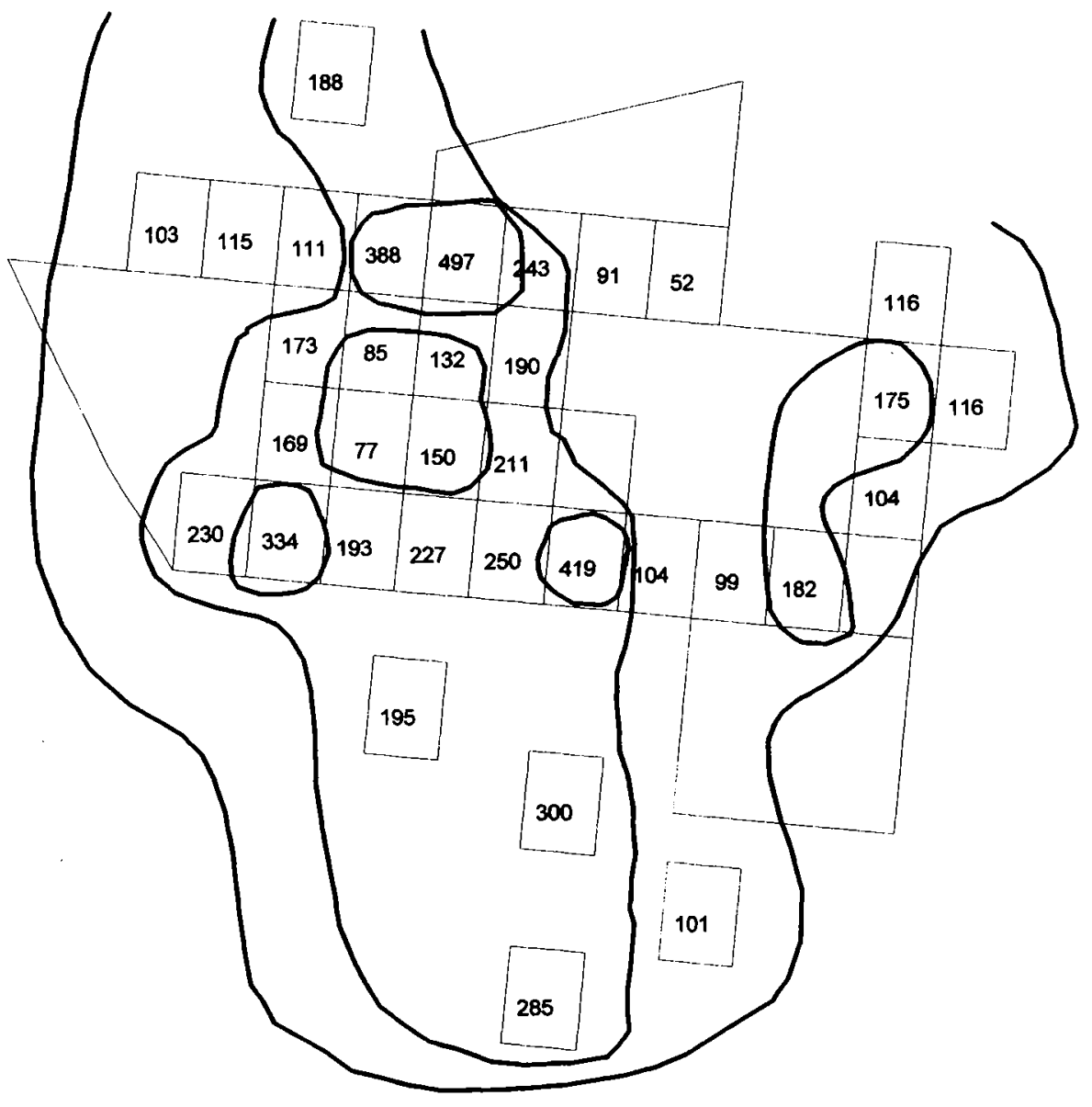

$\begin{array}{llll}10 & 0 & 10 \quad 20 & \text { Meters }\end{array}$

LSE3 Visibility-corrected total pottery

Fig. 14 


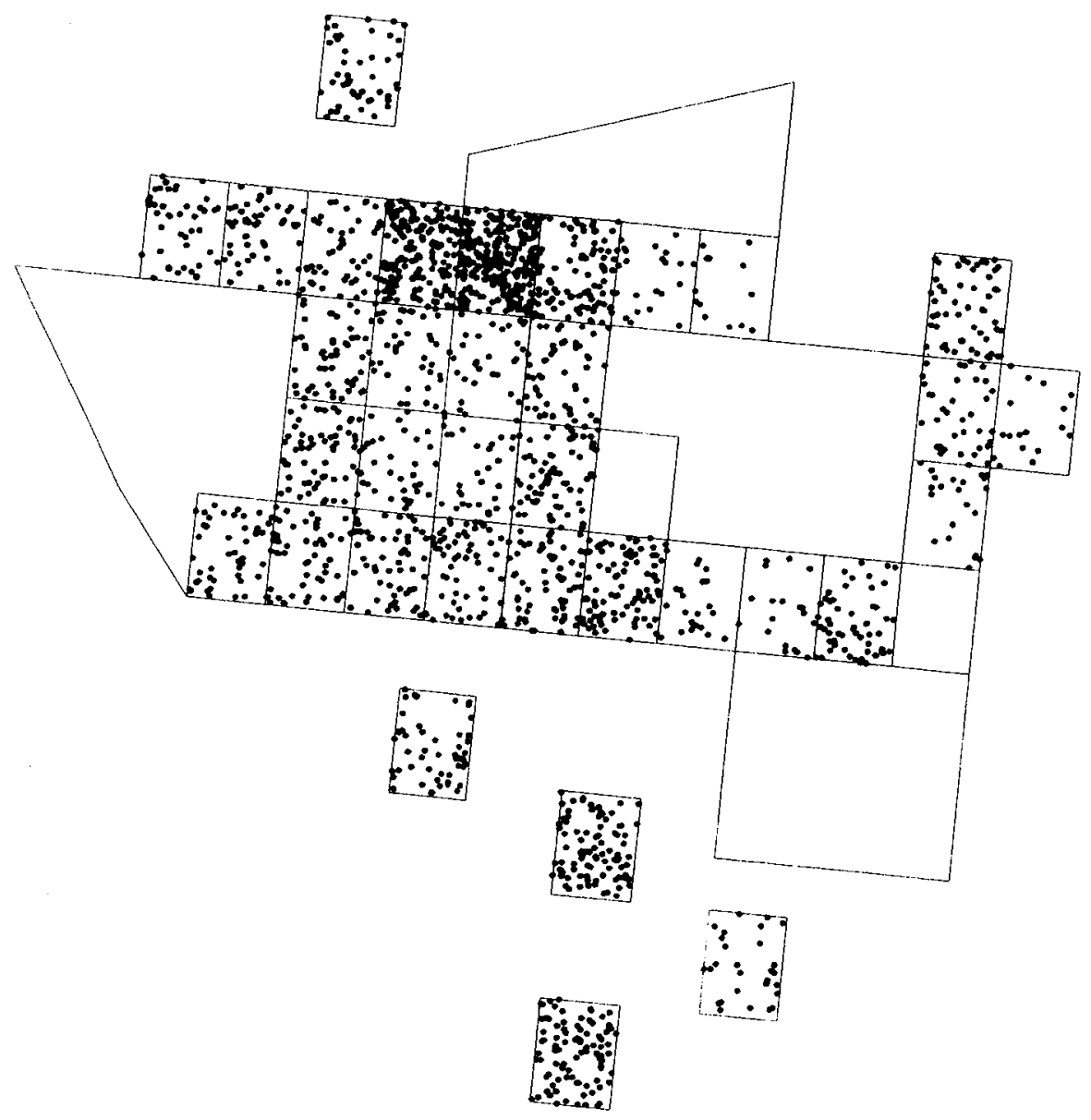

$\begin{array}{llll}10 & 0 & 10 & 20\end{array}$ Meters

LSE3

Visibility-corrected tile

Fig. 15 


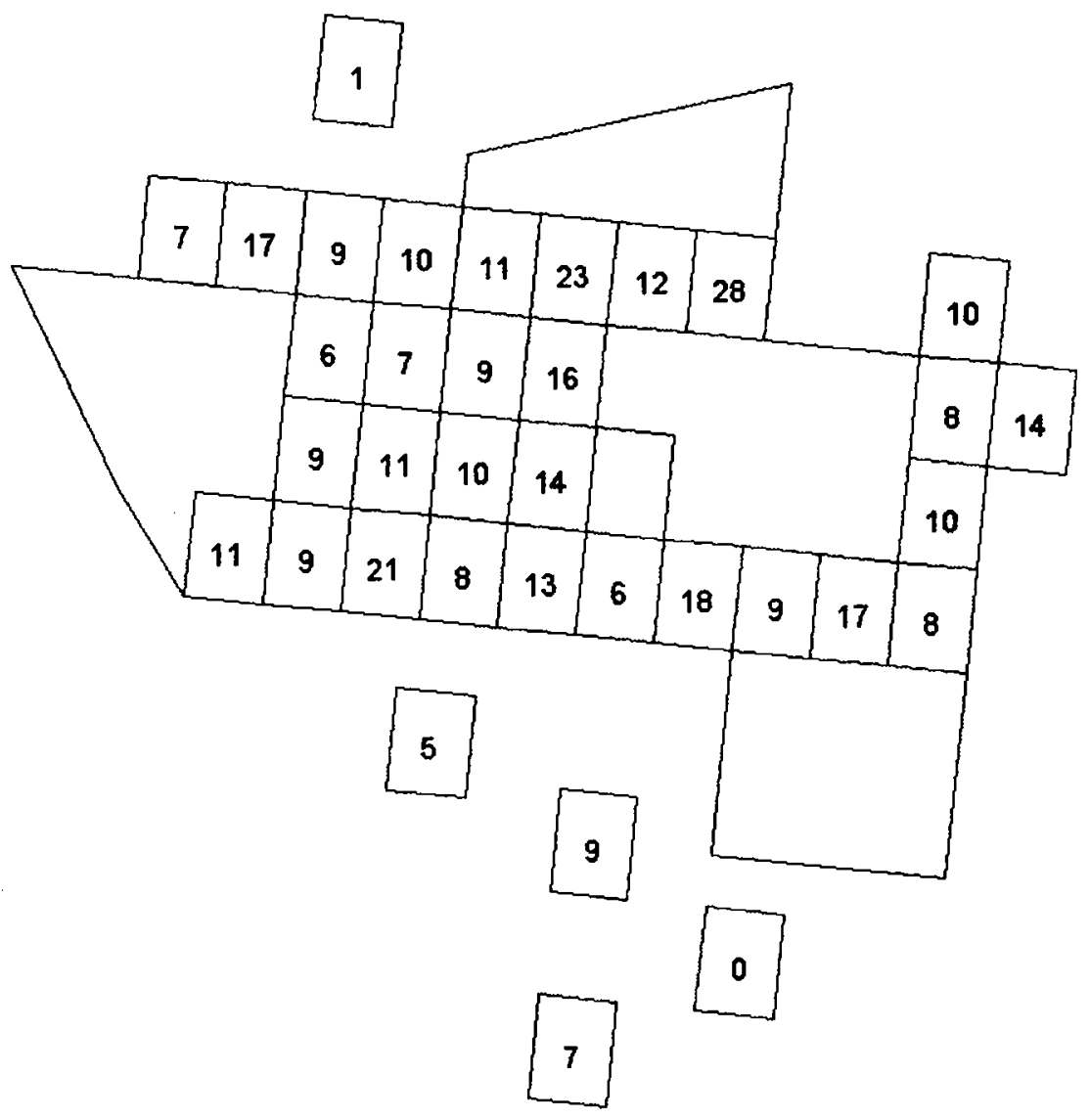

LSE3

Sample fraction (\%)

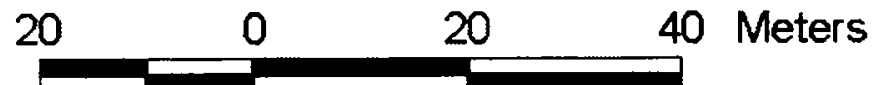

Fig. 16 


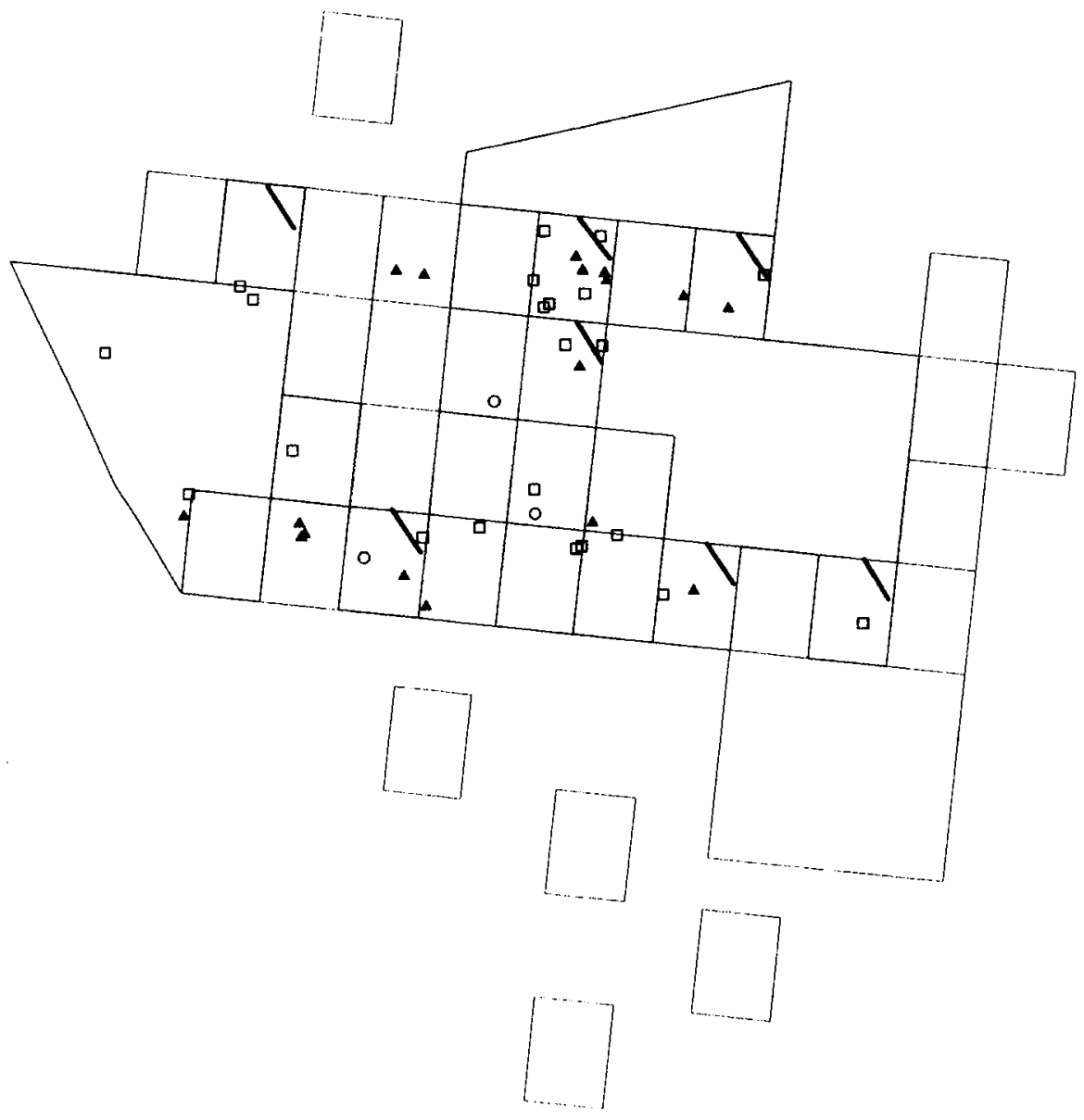

$\begin{array}{llll}10 & 0 & 10 & 20\end{array}$ Meters

LSE3
$\mathbf{R}$

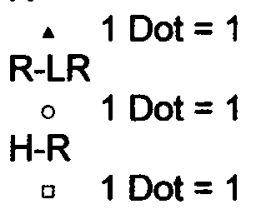

Fig. 17 
spreads across into more normal units and is therefore likely to reflect genuine activity foci. Overlap period wares are by their very nature less reliable on multiperiod sites, as they can well combine features of two different period distributions. In this case, we argue from the total data for this site (not all shown here) that it began as a large Classical Greek farmsite, which shrank to a much smaller farm or even seasonal agricultural base in Roman times, before becoming merely a field area in Late Roman times. The overlap finds shown here fit this model well: the $\mathrm{H}$-R finds are more widely-distributed than $\mathrm{R}$, but also cluster with the $\mathrm{R}$ (some thus mirror the larger site of Classical-Hellenistic times); the R-LR finds are the rarest of the three types shown, and seem to fit on and between the two foci - with minimal LR activity at the site they are probably less-firmly datable evidence for the $\mathrm{R}$ use of the site.

Demonstrating that minor periods show a non-random structure of distribution across the site is very helpful when numbers collected are small, and the risks of contamination through 'offsite' use across the site increased. We needed to find parameters for the trends in district offsite pottery against which the site finds could be set, to identify in a more rigorous way whether the density of finds in any period on the site were truly elevated above local offsite expectation. Figure 18 displays the chronological breakdown for the offsite fieldwalking sample collections (i.e. essentially non-site sherds) for about one third of the $5.2 \mathrm{sq} . \mathrm{km}$. LSE/THS sector. The histograms for the other two-thirds are almost identical. What we have

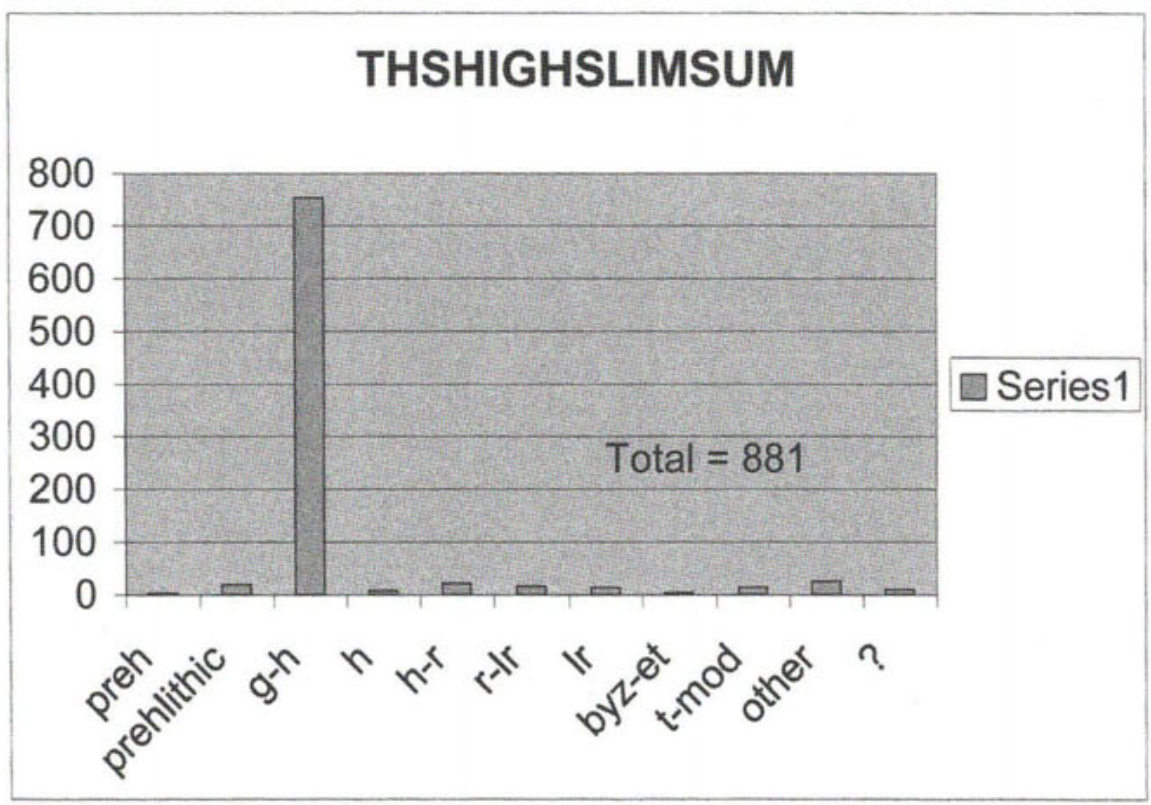

Fig. 18 
done is calculate the overall percentage representation of each phase in the district offsite to provide a generalized expectation of the period makeup of the offsite in the entire sector. As we have seen, after removing the sites and their haloes from the district ceramic density map, it is possible to estimate the density range for background or offsite finds for the area around each site. With these figures we are now in a position to do two related things: firstly to compare site density against expectation for the same fields had no site been there; secondly to give that non-site expected density an estimated chronological composition. One final manipulation: in order to compare and contrast the representation of each period within a site's collection and between sites, we have standardised the actual assemblage collected for dating at each site to a single notional collection figure of 500 sherds. The aim of this series of calculations is to set up a Null Hypothesis: a reconstruction of the likely density and chronological composition of surface ceramic in the fields within which the site is found, had there been no site in use there, must deviate significantly from the counted and dated site collection statistics, on a phase by phase basis, in order to justify any claim for 'site' activity.

Two exceptions may allow a site to retain non-background status, even if the Null Hypothesis is confirmed for the global data for the site grid. If in fact the scatter for any period is not clearly elevated above local background expectation, there remain the final tests of localised clustering or distinctive qualitative features for the finds. In the first case, as seen in the example of figure 17 above, even though a period has few finds at a site, on average comparable to that expected from surrounding fields, non-random focussing of those finds might still be taken to signify enhanced activity within the site area; when collection numbers for one period become limited, small number statistics work against complete accuracy of modelling (especially as the basis for comparison - the dated sample of all offsite pot - is in itself a small sample). Nonetheless it is probable that discard activity at background levels but with a non-random area of deposition at a known site implies a form of site use in that phase in contrast to standard domestic activity; in the case of non-ritual and funerary material, we might suggest seasonal/temporary use of the site. The second case is indeed one we have witnessed earlier - small burial plots where density may for good reason fall below that of surrounding fields with higher background counts, and where the contexts also yield limited numbers of sherds but often of special wares. Clearly, however, there may be occasions when some doubt still remains as to the exact status of the finds of a particular period at a site, given the cumulative processes of averaging of data, the necessary extrapolations in our calculations, and the constant problem of small number statistics. Nonetheless our ongoing analysis suggests that although such final uncertainties do occur on individual sites, the nature of site use leaving such ambivalent indications is unlikely to represent major activity, hence allowing us to group these phenomena into a class of limited or doubtful focussed activity.

Let us follow the main Null Hypothesis methodology through in the case of site THS4 (figure 19). As can be seen, the 'residual' proportion of Classical Greek finds $(\mathrm{A}-\mathrm{H})$ is not very significant, and we argue this to reflect offsite manuring 


\section{SITE THESPIAE SOUTH 4:}

RESIDUALS: If the background is 2500 , and the counts across the site are in transects of 15,893 average, then $16 \%$ of the material ought to be offsite, $84 \%$ site. For a standard module of 500 sherds $=80$ offsite to be found on the site area. Based on the expected representation for the THS Low sector in offsite of $75 \% \mathrm{~A}-\mathrm{H}$, $3.7 \%$ R, $2.85 \%$ LR, and $1.66 \%$ MED (includes Early Turkish):

$\begin{array}{llll} & \text { A-H } & \text { R } & \text { LR } \\ \text { Expected } & 60 & 3 & 2 \\ \text { Actual } & 69 & 32 & 123 \\ \text { Residual } & 10 & 29 & 121 \\ & & & \\ \text { Period } & 5-600 & 400 & 200 \\ \text { length } & \text { years } & \text { years years }\end{array}$

Fig. 19

material. In Early Roman times (R) there is a much greater discrepancy to the advantage of the site collection, and yet absolute numbers are very low, allowing us to suggest that there was focussed activity at the site in this period, but almost certainly of limited and perhaps seasonal or temporary form. Finally the Late Roman (LR) collection reveals a startling contrast, with a huge differential from background expectation confirming major site occupation. It is worth noting that although $\mathrm{R}$ finds are less than those of $\mathrm{A}-\mathrm{H}$, the total imbalance between their representation in the district offsite makes the $\mathrm{R}$ collection much more significant when found on a site grid. Indeed both the high level of background across the entire LSE/THS survey sector (averaging at $\mathbf{2} 635$ sherds per hectare visibility-corrected, or 1 sherd every 4 sq.m.) and its predominantly Classical Greek composition, mean that any group of fields would tend to look like an ancient settlement site to field surveyors used to landscapes without manuring scatters.

Figure 20 will serve as a good illustration for this point. The fieldwalkers identified a site LSE2 in the near vicinity and east of the ancient city of Thespiae, where offsite carpets as noted earlier are especially dense. The gridded collection however failed to reveal structure in the site, and the material was generally very worn and typical for field manuring rather than ploughed-up occupation-level material. 


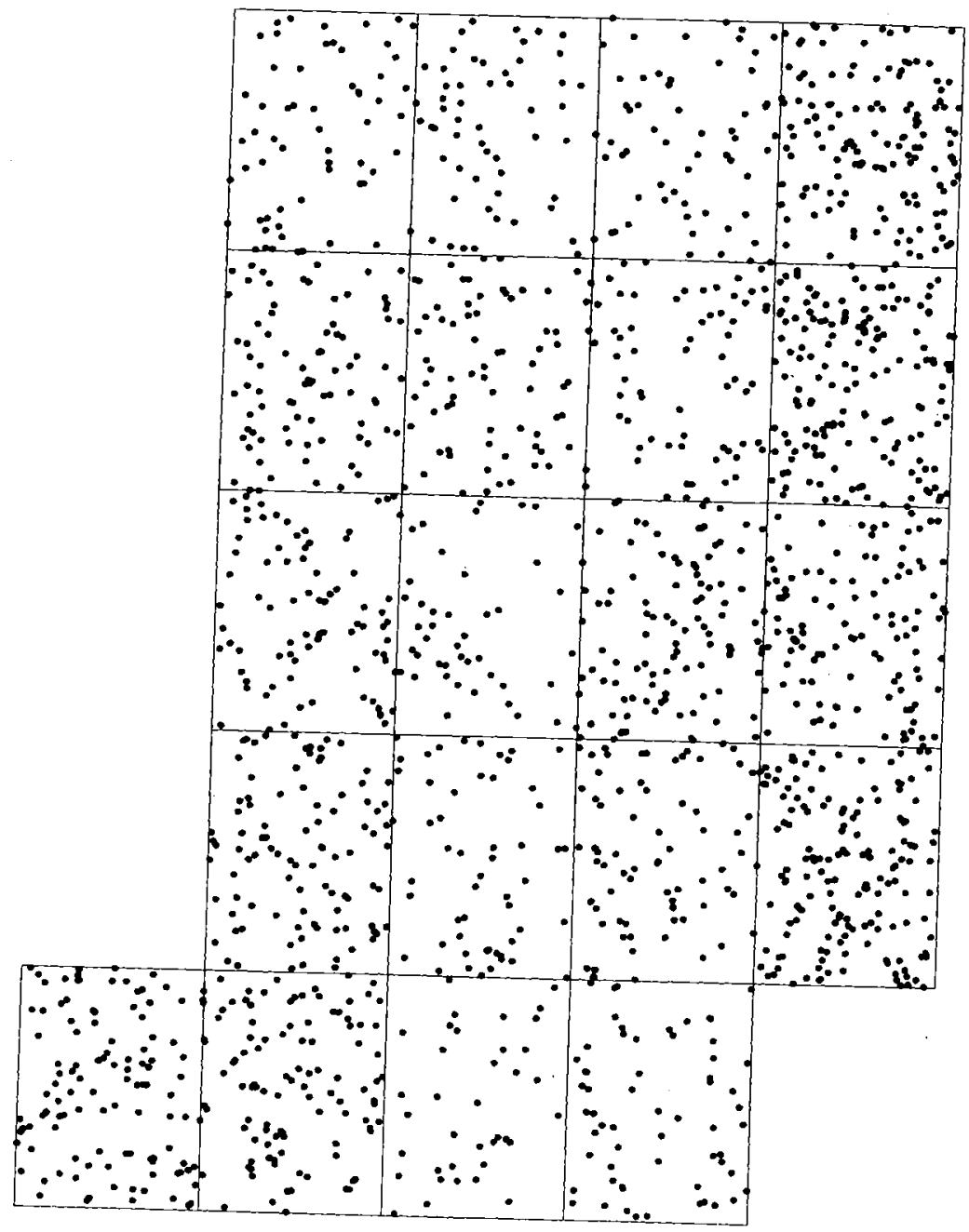

\begin{tabular}{llll}
$4 \quad 0$ & $4 \quad 8$ & Meters \\
\hline & &
\end{tabular} Lse2

- 1 Dot $=1$

\section{LSE2}

Fig. 20 
As the dot-density map shows, a generally randomised scatter is apparent. The slightly elevated density block of four grid-units in the east of the site is due to a change in land-use across a north-south field boundary; this did allow us to observe another potential problem - where a freshly-ploughed field (visibility-reading 10) lies adjacent to one with dense stubble (visibility 1-2), the very common sighting of sherds in the first case and the very rare sighting in the second tends even with visibility-correction to leave a residual contrast across that boundary, owing to the linear nature of the correction applied. Visibility-corrections can be shown to produce much smoother transitions across varying land-uses in the middle ranges of visibility.

LSE2 was a helpful test of the methodologies outlined so far, but it remains on our list of sites because it survived elimination through passing the last test for site eligibility on the list given above. It showed no significant density elevation or internal structure for the global finds for the site, and its representation for Classical Greek, Roman and Medieval times was consistent with fields near the ancient city/medieval village of Thespiae and nothing more. But ... the dated collection (figure 21) produced a small but highly non-random clustering of prehistoric ceramic and lithic finds. We would argue (see Bintliff, Howard, Snodgrass, 1999) that such minimal numbers of finds are likely to be all that can be seen of small farm sites of the earlier phases of the Bronze Age in Greece, for reasons of taphonomy and fieldwalking methodology.

How reproducible are our new approaches as we process site after site from the several hundred identified by the Boeotia Project? Let us return to a site which we already looked at in its offsite context - LSE1, but now in its internal evidence. Figure 22 plots the dated sample for the Classical Greek period. This phase dominated the dated collection, and despite the nearness to Thespiae city, was still significantly elevated above background expectation, as the Residual Analysis chart below confirms:

\begin{tabular}{lrrr}
\hline & A-H & R & LR \\
\hline Actual & 305 & 83 & 22 \\
Predicted & 204 & 21 & 10 \\
RESIDUAL & +101 & +62 & +12 \\
\hline
\end{tabular}

In fact the global surface 'shape' of the site is essentially created by this one dominant period, since the density contours are largely controlled by the peaks and lows of the Classical Greek material. Here it is critical to note that, once we decide that a Classical Greek concentration is indeed a site rather than offsite material, all the sherds of that age are reinstated as site, since city manuring would not have been layered across a rural farmsite or cemetery, etc. The 'predicted' offsite city effect here of 204 sherds now is added to the 'residual' above-expectation sherds which indicate site status, creating at 305/500 sherds a clear dominance for that single phase of use of the site, and hence - largely creating the density anomaly which makes the site recognisable in the first place. 


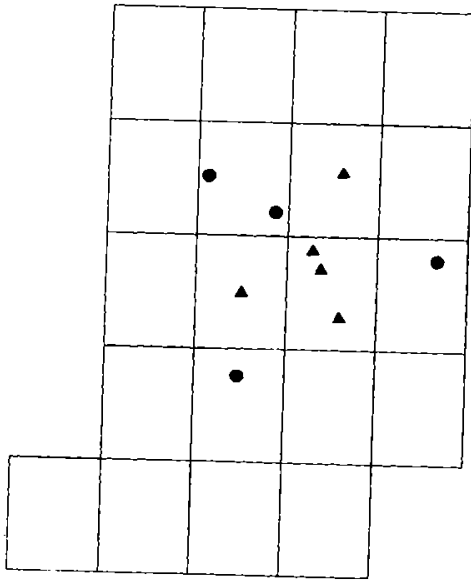

10 $0 \quad 10 \quad 20$ Meters

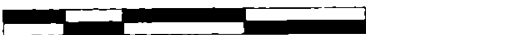

\section{LSE2}

Fig. 21

In contrast, the Early Roman phase, from the Residual chart, produced a far lower quantity of finds, yet the elevation above expectation was very pronounced. Figure 23 provides the explanation for these apparently conflicting trends: a very clear non-random focus of activity in a limited part of the site. If the Classical Greek use is postulated at full site activity across the whole grid, then the Roman use is suggested as a shrunken occupation phase. As for Late Roman, the Residual chart does not impress with strong contrast against expected values - and as noted earlier, with such low numbers predicted for background and actually recovered, small number statistic biasses warn us against making much of minor fluctuations in the exact figures being used. The distribution of LR finds (figure 24) - if we subtract the dubious bunching of double-finds in two high sample-fraction units (tagged) in the south-west of the site, is very much the kind of random and wide dispersal we would expect of non-focussed background activity. 


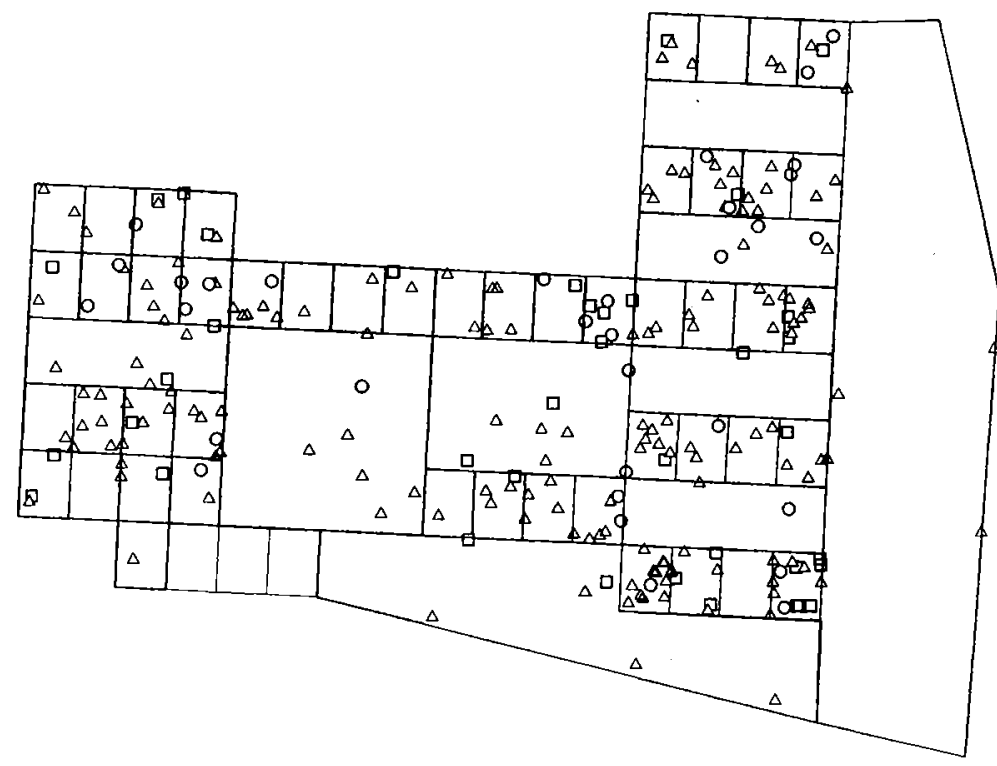

LSE1

50 Meters

\section{Grab A-H \\ 1 Dot $=1$ \\ Grab C-H \\ Grab C \\ 1 Dot $=1$ \\ ㅁ 1 Dot $=1$ \\ A-H
- 1 Dot $=1$
C-H \\ C \\ 1 Dot $=1$ \\ - 1 Dot $=1$}

Fig. 22

Although many of the sites analysed so far in the LSE/THS sector are Classical Greek occupation/cemetery sites with either shrunken use in Roman and Late Roman times on a putative permanent or temporary basis, or merely offsite activity traces in these phases, there are as many where Roman or Late Roman use is significant or even the dominant phase in the site's flourishing. Such contrasting scenarios are important to allow us to counteract any suspicion that the systematic downscaling of activity traces when we compare one period against another is 


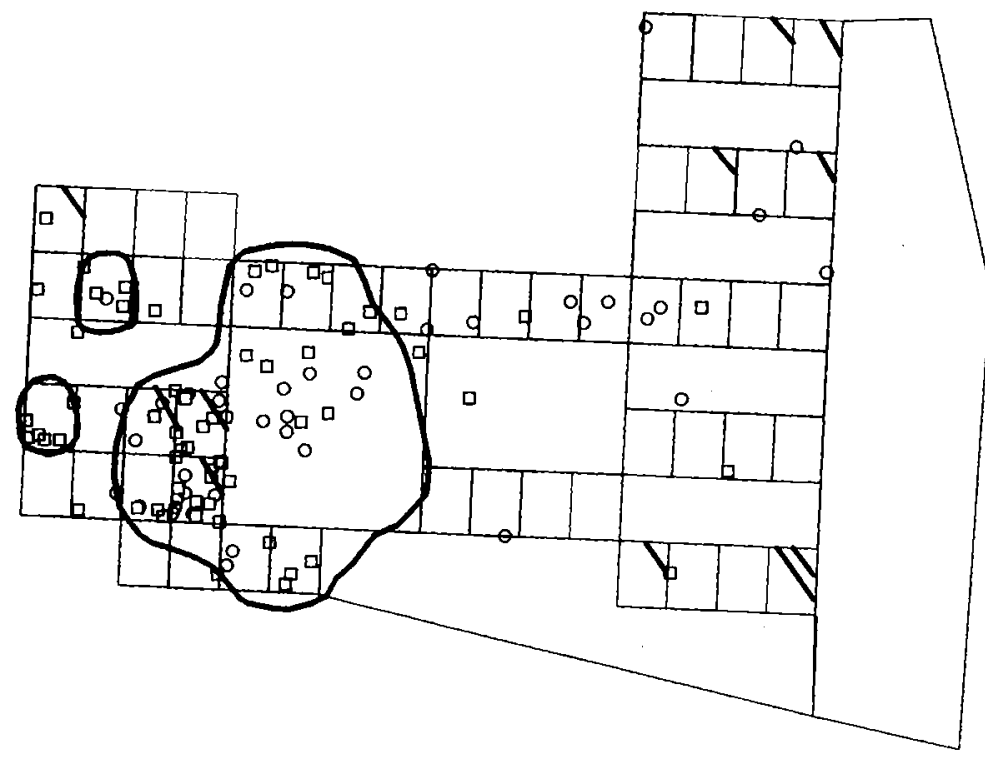

LSE1

Grab R

ㅁ 1 Dot $=1$

Grab H-R

- 1 Dot $=1$

R

ㅁ 1 Dot $=1$

H-R

- 1 Dot $=1$

Fig. 23

largely due to a general change in the production and distribution of ceramics across time (cf. the case made for the Ager Tarraconensis Survey in Spain - Carreté et al., 1995). That is not to say that there is not evidence for such intrinsic variability across the major historic periods in Greece, but so far our analysis suggests that greater discard of pot in some periods compared to others is much less important than the differences created by the changing status of particular sites along a spectrum from: suspected largescale, permanent residential use for multifunctional activities; through smaller-scale permanent use perhaps for a lesser range of activities; then into even less-intensive, seasonal or temporary use of a location for a limited range of activity; and finally into offsite activity in which the site is treated very much as surrounding fields. We might conveniently slot the small rural burial class of site into the third category. 


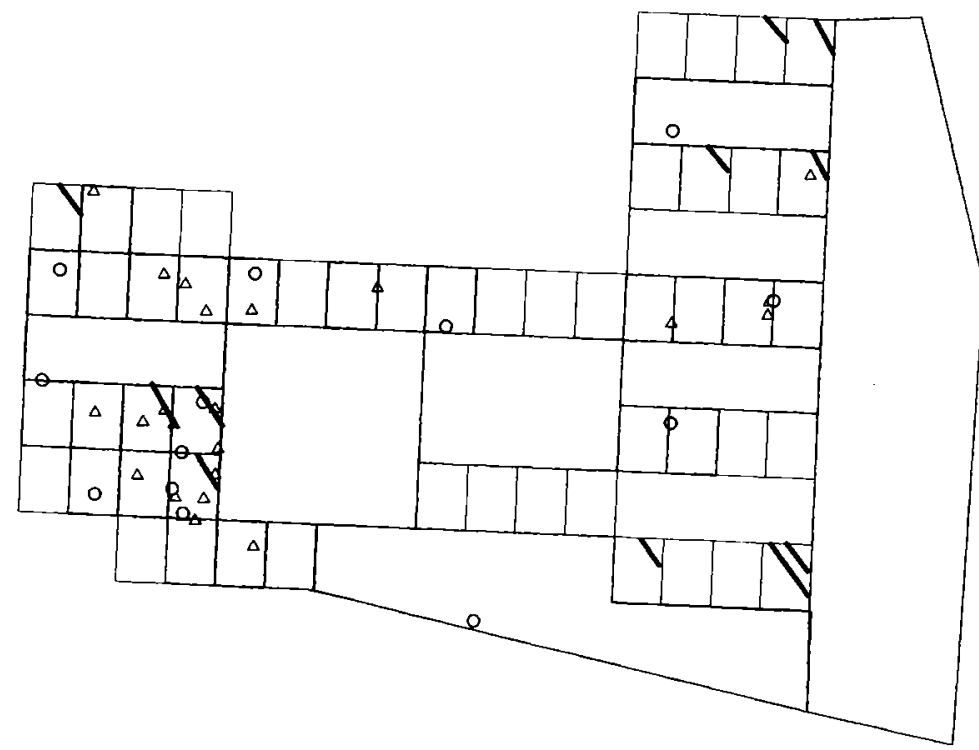

\section{LSE1}

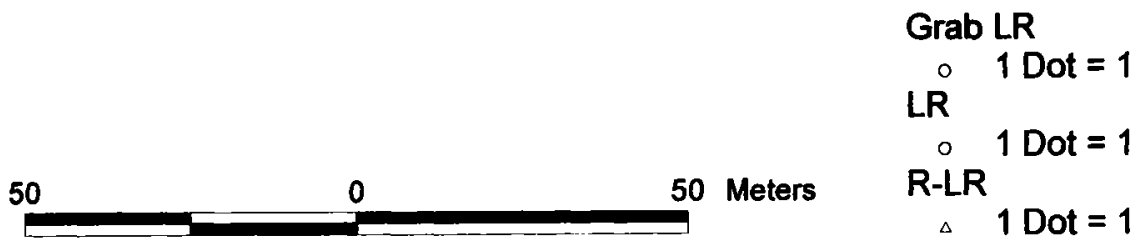

Fig. 24

To illustrate this last point we can look at one of the sites so far analysed where the elusive Roman presence in our landscape finally bursts into site dominance site LSE7. Figure 25 displays the surface contouring of the site, with impressive densities peaking in the east-centre sector (the two grab samples in the lower half of the figure relate to finds collected between the arms of the formal rectangular grid units). In figure 26 we see the plot of generic Classical Greek finds from the dated sample collection. The closely-dated 'Classical' (ie 5th-earlier 4th century BC) finds are strongly-focussed in the western part of the site, as are the overlap-period finds of Classical to Hellenistic date (C-H); nonetheless these finds constitute less than $10 \%$ of the dated collection (90/notional 500 standard sample). 
The Residual Analysis:

\begin{tabular}{llrr}
\hline & A-H & \multicolumn{1}{c}{ R } & \multicolumn{1}{c}{ LR } \\
\hline Expected & 44 & 4 & 2 \\
Actual & 90 & 120 & 243 \\
Residual & 46 & 116 & 241 \\
\hline
\end{tabular}

shows that generic Classical Greek finds are well-above expectation for local background, yet numerically slight compared to the other key phases of site use. It is reasonable to explain this through a limited area of the site in use in this first phase, if still at full domestic level. Both the Early and Late Roman finds are dramatically beyond comparison with the low background expectation for this locality. Whilst the Early Roman plot suggests a marked expansion of site size, suiting the elevated levels above those of the less extensive Classical Greek site, Late Roman finds (figure 27) displays the densest and most widespread scatter of dated sherds. Clearly that last period created the essential global contours of surface density recorded by the density plot across the site, and would have been the time when the site saw most concentrated and extensive use (all the more marked when we consider that the finds specifically characterised as ' $L R$ ' proper should be largely attributable to a phase of some 200 years, in contrast to the 5-600 years for potential generic Classical Greek use, and the 400 for Early Roman use).

Figure 28 summarizes the key statistics and provisional interpretation of the sites so far analysed using our new methodology within the LSE/THS sector. Note that the variable numbers of sherds collected for dating from each site have been standardised to a sample size of 500 sherds to enable direct comparison.

\section{Conclusions}

One of the features that has struck us forcefully is the inadequacy of simple numerical indications from the site/offsite comparison and from the intra-site statistics - revealed clearly in the way in which this table shows how at times quite different counts can be given a similar interpretation, whilst at other times similar counts are given quite different interpretations, in site use terms. We think we have been able to demonstrate that far more complex considerations have to be brought to bear in distinguishing between landscape activity in the site locality and focussed, site-based activity. The same comment applies equally well to study of the internal density and chronological composition of site ceramics. We accept that the final interpretations offered - albeit currently - for the sites presented here, may change with the accumulation of a far greater number of case-studies subjected to the methodology, and indeed as a result of the process of constructive criticism by colleagues working with other surface surveys. However we remain convinced that surveys must now collect information at a level of detail allowing 


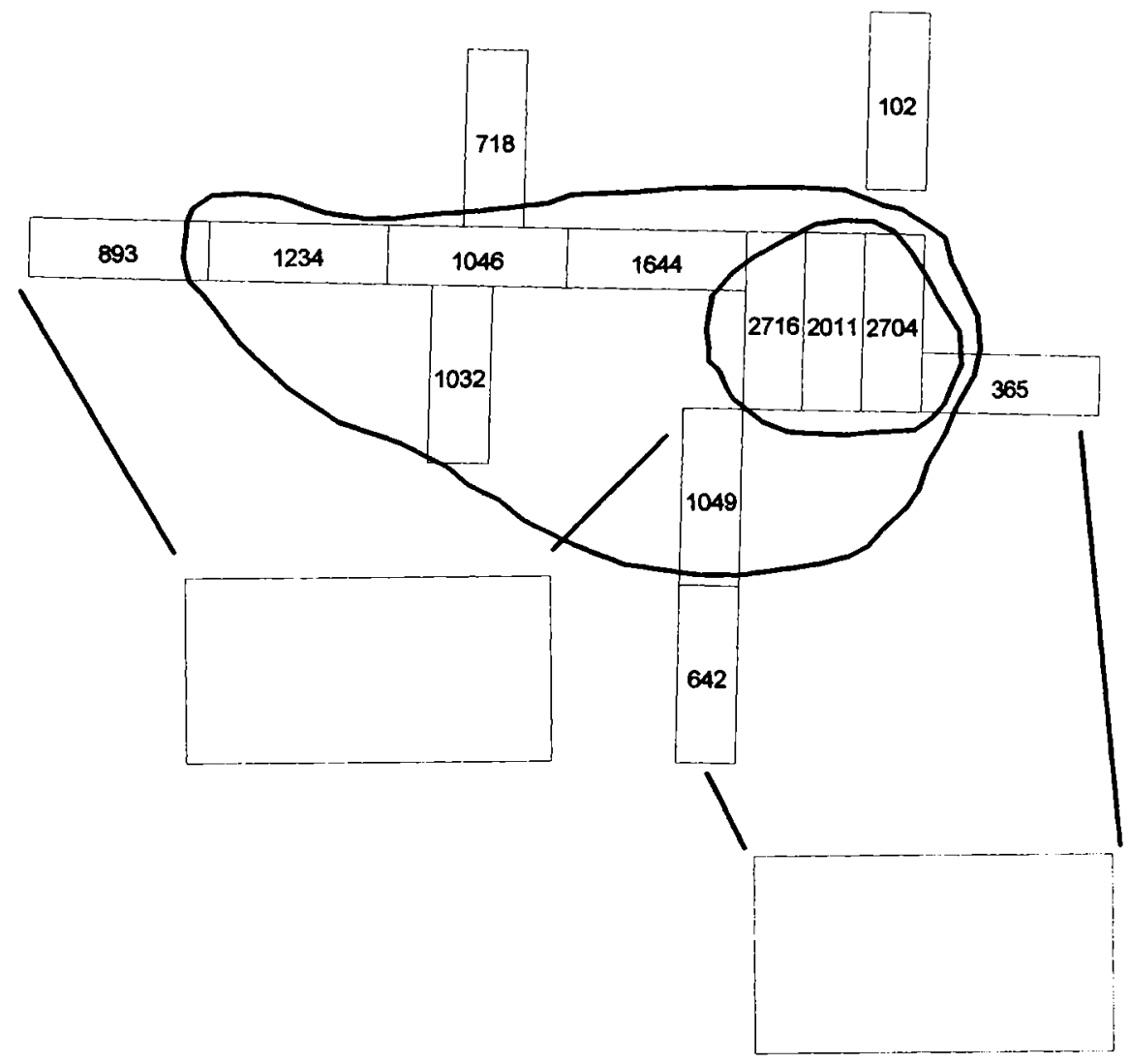

LSE7 Visibility-corrected total pottery

50 0

50 Meters

Grab samples Ise7

Fig. 25 


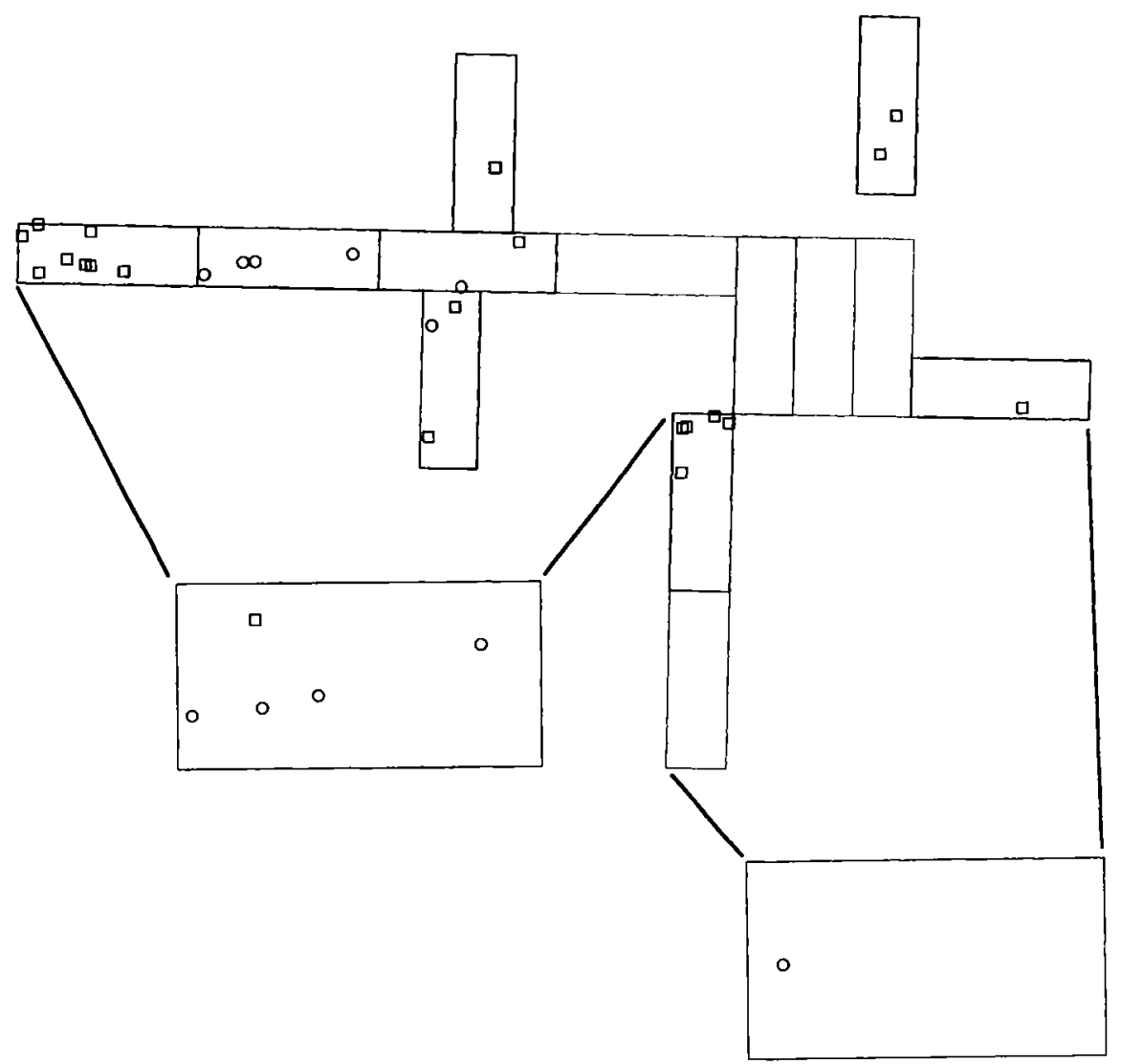

LSE7

\section{C-H grab}

ㅁ 1 Dot $=1$

$C$ grab

$$
\begin{array}{cr}
C-H & 1 \text { Dot }=1 \\
\text { C } & 1 \text { Dot }=1 \\
\therefore & 1 \text { Dot }=1
\end{array}
$$

Abb. 26 


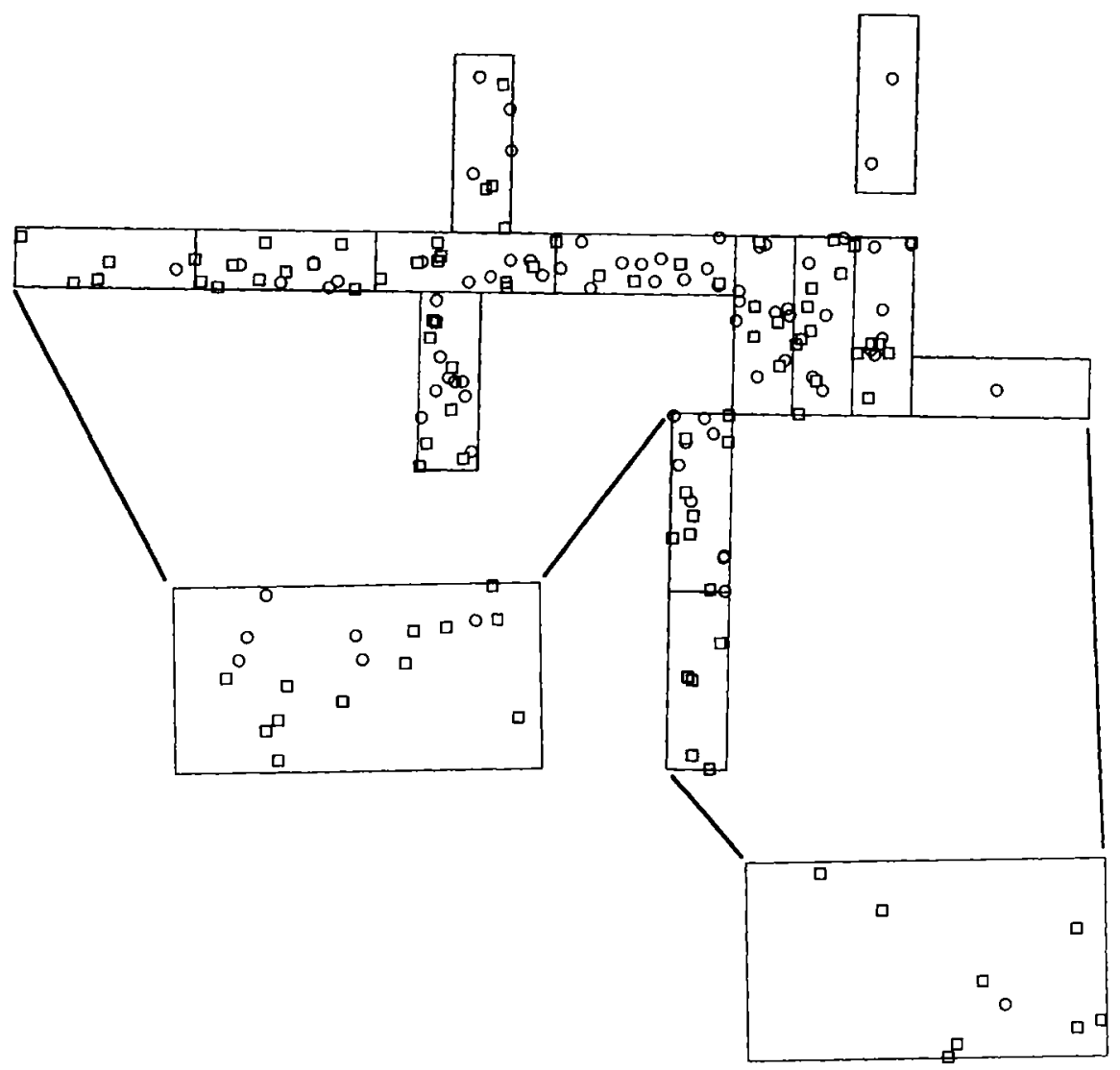

\section{LSE7}

50

$0 \quad 50$ Meters
LR grab

a 1 Dot $=1$

R-LR grab

$\begin{array}{cc}\text { LR } & 1 \text { Dot }=1 \\ \text { R-LR } & 1 \text { Dot }=1\end{array}$

Fig. 27 


\section{PROVISIONAL SITE INTERPRETATION}

Per 500 sherds:

\begin{tabular}{llllll} 
& A-H & \multicolumn{2}{c}{ L } & LR \\
LSE1 & 305 & $\begin{array}{l}\text { Full occ site } \\
\text { + rural sanc. }\end{array}$ & Smaller occ site & 22 offsite? \\
LSE2 & 237 & $\begin{array}{l}\text { Offsite } \\
\text { 32 }\end{array}$ & Offsite & 3 Offsite
\end{tabular}

[But a prehistoric site!]

\begin{tabular}{|c|c|c|c|c|c|}
\hline $\begin{array}{l}\text { LSE3 } \\
\text { LSE4 }\end{array}$ & $\begin{array}{l}425 \\
416\end{array}$ & $\begin{array}{l}\text { Full occ site } \\
\text { Cemetery }\end{array}$ & $\begin{array}{l}30 \\
13\end{array}$ & $\begin{array}{l}\text { Smaller low act. } \\
\text { offsite }\end{array}$ & $\begin{array}{l}6.5 \text { offsite? } \\
4 \text { offsite }\end{array}$ \\
\hline LSE5 & 443 & Full occ site & 41 & Smaller low act. site & ? 4 offsite \\
\hline LSE6 & 345 & Full occ site & 67 & Reduced act & 29 Offsite \\
\hline LSE7 & 90 & $\begin{array}{l}\text { Small occ } \\
\mathrm{H} \text { status uncl }\end{array}$ & $\begin{array}{l}120 \\
\text { lear }\end{array}$ & $\begin{array}{l}\text { Middle occ site } \\
\text { Especially MR }\end{array}$ & 243 Full occ \\
\hline $\begin{array}{l}\text { THS1 } \\
\text { [Cemetery] }\end{array}$ & 120 & Full 'occ' & 0 & Offsite & 0 Offsite \\
\hline THS2 & 77 & Offsite & 47 & medium occ site & 166 Full occ \\
\hline THS3 & 115 & $\begin{array}{l}\text { (Small occ??) } \\
\text { low activity }\end{array}$ & 57 & Small occ/low act. & 223 Full occ \\
\hline THS4 & 60 & Offsite & 32 & Small occ site & 123 Full occ \\
\hline THS11 & 358 & Cemetery & 45 & Offsite & 40 Offsite \\
\hline THS12 & 175 & Full occ. & 74 & Full occ.site & 88 Full occ.site \\
\hline THS13 & 77 & Offsite & 63 & Small occ.site & 219 Full occ.site \\
\hline THS14 & 36 & Offsite & 12 & Offsite & $\begin{array}{l}133 \text { Full occ } \\
\text { MEDIEVAL } \\
213 \text { Full occ }\end{array}$ \\
\hline tS15 & 439 & Cemetery & 3 & Offsite & 0 Offsite \\
\hline THS16 & 237 & Large occ. & 91 & Medium-Large occ. & 60 Offsite \\
\hline AS17 & 306 & Full use occ. & 53 & Low activity & 25 (low act.-) offsite \\
\hline
\end{tabular}

Fig. 28

the problems and solutions proposed in this paper to be put to further testing and improvement, even if this means a slower rate of progress across the landscape and the abandonment of short-cuts such as excessive subsampling of landscapes and site surfaces.

Within the scope of this paper we have avoided specific reference to complementary analyses being applied to the same LSE/THS data. One important tool, for example, which we already have good and indeed counter-intuitive results from, is viewshed analysis, examining the intervisibility of putative settlement sites with each other, contemporary rural burial sites, and the city of Thespiae. Another approach, in the hands of co-director Anthony Snodgrass, and 
especially relevant to questions raised and hypotheses made in this paper - is that of the functional composition of the assemblage from each site, by phase; we are optimistic that this will give us independent evidence for differing modes of site activity, not only between sites within each period, but for changes in use across different phases at each site (promising pioneer work of this kind has been carried out by Todd Whitelaw on data from the Keos Survey - Whitelaw, 1998).

\section{Notes}

1. An earlier version of this paper has appeared in: Pharos. Journal of the Netherlands Institute at Athens, VII, 51-91. This version incorporates some revisions and has a different selection of illustrations.

\section{Acknowledgements:}

The surface survey of the LSE/THS rural district, as part of the Bradford-Durham-Cambridge Boeotia Project, was carried out by the Cambridge team, under the direction of Professor Anthony Snodgrass, in the late 1980s and early 1990 s. Dr. Mark Gillings (Leicester University) undertook the initial data-entry and digitisation of the offsite fieldwalking transects and their numerical ceramic and visibility values, and Dr. Kostas Sbonias (Corfu University) directed the dataentry process for offsite and site artefact lists. The further digitisation of site records and GIS investigation presented here is the work of Phil Howard, whilst the methodological procedures for site and offsite activity analysis and consideration of the wider interpretative issues is the work of John Bintliff. Professor John Hayes (Oxford University) identified the historic-era ceramics, Oliver Dickinson those of prehistoric date. The Boeotia Project has flourished owing to the outstanding encouragement and practical assistance given to it by the current Ephor of Antiquities for Boeotia, Dr. Vassilis Aravantinos, whilst our accommodation has been thanks to the kindness and foresight of his eminence Hieronymus Bishop of Livadheia.

\section{Bibliography}

Bintliff, J. L. (1992), Appearance and reality: Understanding the buried landscape through new techniques in field survey, in: M. Bernardi (ed.), Archeologia del Paesaggio (Firenze) 89-137

Bintliff, J. L. (1997), The role of science in archaeological regional surface artefact survey, in: D. Dirksen and G. von Bally (eds.), Optical Technologies in the Humanities (Berlin) 9-28

Bintliff, J. L. (1998), The Boeotia Project 1997 season, in: Archaeological Reports 21 (1997)

(University of Durham and University of Newcastle upon Tyne 1998) 89-95 
Bintliff, J. L., B. Davies, C. Gaffney, A. Snodgrass and A. Waters (1990), Trace metal accumulation in soils on and around ancient settlements in Greece, in: S. Bottema, G. Entjes-Nieborg and W. V. Zeist (eds.), Man's Role in the Shaping of the Eastern Mediterranean Landscape (Rotterdam) 159-172

Bintliff, J. L., P. Howard and A. M. Snodgrass (1999), The hidden landscape of prehistoric Greece, in: Journal of Mediterranean Archaeology 12.2 (1999) 139-168

Bintliff, J. L. and A. M. Snodgrass (1985), The Boeotia survey, a preliminary report: The first four years, in: Journal of Field Archaeology 12 (1985) 123-161

Bintliff, J. L. and A. M. Snodgrass (1988 a), Mediterranean survey and the city, in: Antiquity 62 (1988) 57-71

Bintliff, J. L. and A. M. Snodgrass (1988 b), Off-site pottery distributions: A regional and interregional perspective, in: Current Anthropology 29 (1988) 506-513

Carreté, J.-M., S. J. Keay and M. Millett (1995), A Roman Provincial Capital and its Hinterland: The Survey of the Territory of Tarragona, Spain. Journal of Roman Archaeology Supplement 15 (Michigan 1995)

Cherry, J. F. J. C. Davis and E. Mantzourani (eds.) (1991), Landscape Archaeology as LongTerm History (Los Angeles)

Snodgrass, $A$. (1994), Response: the archaeological aspect, in: $I$. Morris (ed.), Classical Greece. Ancient Histories and Modern Archaeologies (Cambridge) 197-200

Snodgrass, $A . M$. and J. L. Bintliff (1991), Surveying ancient cities, in: Scientific American (1991) 88-93.

Whitelaw, T. (1998), Colonisation and competition in the polis of Koressos, in: L. Mendoni (ed.), Kea Conference (Athens) 227-257

Wilkinson, T. J. (1994), The Structure and Dynamics of Dry-Farming States in Upper Mesopotamia, in: Current Anthropology 35 (1994) 483-520 